\title{
On the discovery and development of tandem 1,4- and 1,2-addition of phosphites to 1-azadienes
}

\author{
Frederik E.A. Van Waes, Wouter Debrouwer, Thomas S.A. Heugebaert, \\ and Christian V. Stevens* \\ Research Group SynBioC, Department of Sustainable Organic Chemistry and Technology, Faculty \\ of Bioscience Engineering, Ghent University, Coupure links 653, B-9000 Ghent, Belgium \\ E-mail: Chris.Stevens@UGent.be
}

In honour and in memory of Prof. Alan R. Katritzky

DOI: http://dx.doi.org/10.3998/ark.5550190.0015.100

\begin{abstract}
Over the past 15 years we have developed a one-step protocol for the synthesis of 3-phosphonylated aminophosphonates from $\alpha, \beta$-unsaturated imines through tandem 1,4-1,2-phosphite addition. This account covers the initial development, mechanistic implications of using different phosphite nucleophiles and the expansion towards oximes, hydrazones and unsaturated imines included in aromatic sextets, e.g. quinolines, phenanthrolines and napthyridines.
\end{abstract}

Keywords: Phosphonylation, diphosphonylation, tandem addition, $\alpha, \beta$-unsaturated imines, $\alpha, \beta$ unsaturated hydrazones, $\alpha, \beta$-unsaturated oximes, quinolines, phenanthrolines, naphthyridines

\section{Table of Contents}

1. Introduction

2. Addition to $\alpha, \beta$-Unsaturated Imines

2.1. Using dialkyl trimethylsilyl phosphites

2.2. Using trialkyl phosphites

2.3. Using tris(trimethylsilyl) phosphites

2.4. Mechanistic implications

3. Addition to $\alpha, \beta$-Unsaturated Hydrazones

4. Addition to $\alpha, \beta$-Unsaturated Oximes

5. Diphosphonylation of Aromatic Heterocycles

5.1. Quinolines

5.2. Phenanthrolines

5.3. Naphthyridines

5.4. Other aromatic heterocycles 
5.4. Other activation methods

5.5. Double diphosphonylation

5.6. Oxidation of the diphosphonylated products

5.7. Synthesis of diphosphonic acids

6. Conclusions

\section{Introduction}

Aminophosphonates and their corresponding aminophosphonic acids are known as amino acid mimetics and, therefore, affect the physiological activity of the cell. ${ }^{1-2}$ Similarly, the synthesis of 3phosphonylated aminophosphonates can be of major importance because of their high similarity to glutamic acid. (S)-Glutamic acid (Glu, 1) is the main excitatory neurotransmitter in the central nervous system (CNS) and operates through two main heterogeneous classes of receptors: ionotropic and metabotropic Glu receptors (iGluRs and mGluRs, respectively). Both classes are further subdivided into several subclasses, but the number of functional receptors in the CNS is not known.<smiles>N[C@@H](CCC(=O)O)C(=O)O</smiles>

(S)-Glu (1)<smiles>N[C@@H](CCPOCO)C(=O)O</smiles>

(S)-AP4 (2)<smiles>N[C@@H](CCC[Po]([O-])O)C(=O)O</smiles>

(S)-AP5 (4)

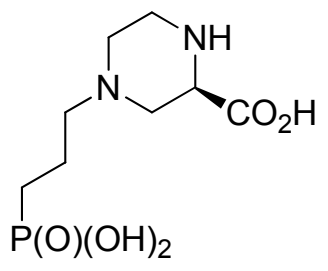

$(R)-\mathrm{CPP}(3)$<smiles>N[C@@H](CCPC(=O)O)[Po]O</smiles>

Scheme 1. (S)-Glutamic acid and phosphonic acid containing analogues.

Selective Glu agonists and antagonists are not only important for the characterization of different Glu receptor subtypes, but also for the treatment of CNS diseases, such as epilepsy, Huntington's disease, Parkinson's disease, dementia, chronic pain, and so forth. Therefore, the Glu receptor field has been, and continues to be, in a state of almost explosive development. ${ }^{3}$ A number 
of phosphonic acid Glu analogues are known as potent selective GluR antagonists or agonists (Scheme 1). Substitution of the carboxylate group by a bioisosteric phosphonic acid group is known to increase receptor selectivity. For example, $(S)$-AP4 (2) is shown as a group III mGluR agonist, some tenfold more potent than Glu. ${ }^{4-6}(S)$-AP5 (4) activates the same group III receptors, but with markedly lower potency and selectivity. $(R)$-AP5 on the other hand can not be shown to interact with mGluRs, but is a potent and selective competitive $N$-methyl D-aspartate (NMDA; iGluR) antagonist. $^{7-8}$ The diphosphonic acid derivative of AP4 (Scheme 1, 5) has been tested several times as a Glu analogue without any activity so far. ${ }^{9-12}$ However, further research into new bioisosteres has been indicated as a fruitful path to new subtype-selective mGluR ligands. ${ }^{3}$

The synthesis of 1-alkylaminophosphonates by the reaction of a dialkyl phosphite and an imine under thermal conditions has been described in the early 1950s. ${ }^{13}$ However, dialkyl phosphites (e.g. 6, Scheme 2) are generally considered to be poor nucleophiles because they exist predominantly in a $\sigma 4 \lambda 5$ configuration ( $6 \mathbf{a}$, coordination number of 4 , valence of 5 ), ${ }^{14}$ and reaction primarily proceeds through a four-membered transition state. Upon treatment of imines with dialkyl phosphites, reaction times of several hours at temperatures above $100{ }^{\circ} \mathrm{C}$ are not uncommon. ${ }^{15}$ These poor reaction speeds can be improved by either basic or acidic catalysis and resultingly, a myriad of catalysts have been introduced to date. ${ }^{16-19}$

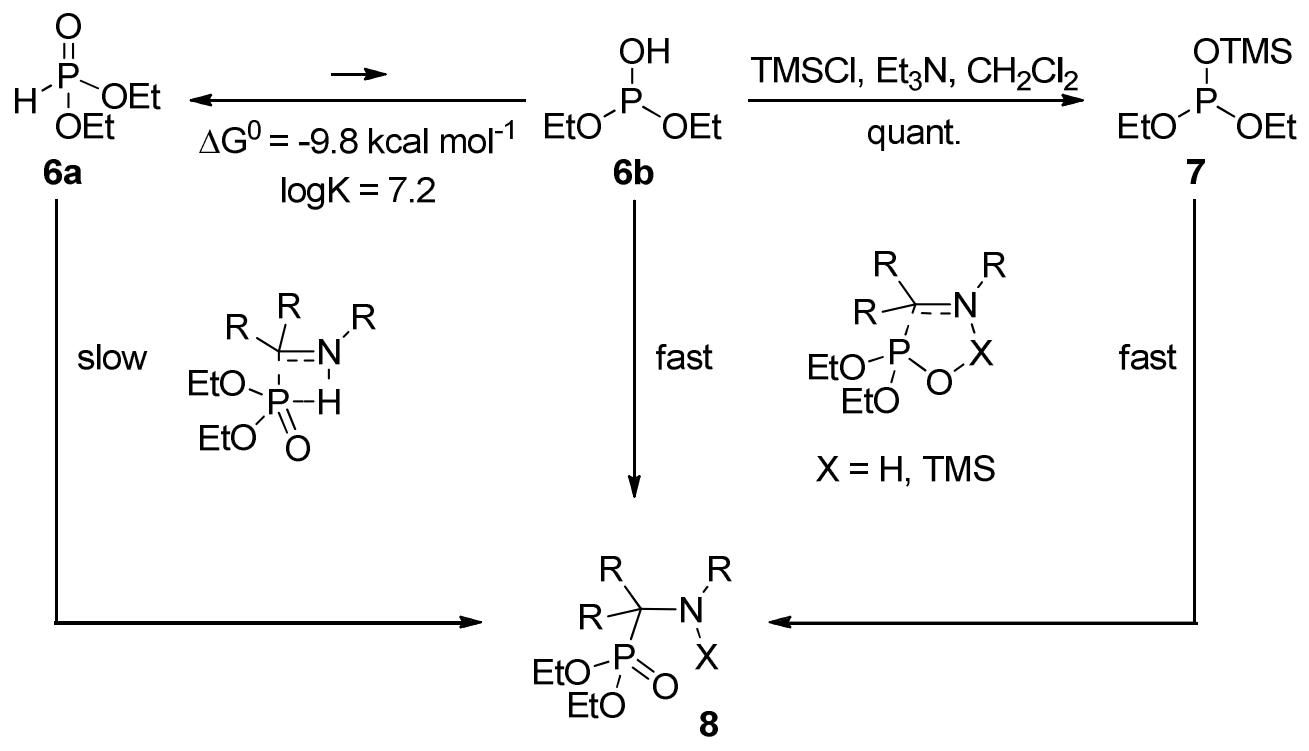

Scheme 2. Mechanisms of the Kabachnik-Fields reaction.

As an alternative to the use of dialkyl phosphites, dialkyl trimethylsilyl phosphites (e.g. 7, Scheme 2) were presented by Afarinkia et al. as excellent mild phosphonylation agents. As an example, the phosphonylation of 2,2-diethoxyacetaldehyde $N$-benzylimine at $110{ }^{\circ} \mathrm{C}$ showed an increase in yield from 55 to $79 \%$ upon moving to silylated phosphites. ${ }^{20}$ The more nucleophilic $\sigma 3 \lambda 3$ form $^{20-21}(\mathbf{6 b}$, coordination number of 3 , valence of 3 ) of the dialkyl phosphite reagent is retained by O-silylation, resulting in increased reaction rates. In addition, fast and exclusive 1,2-addition to $\alpha, \beta$-unsaturated imines containing a phenyl group was reported by the same authors using diethyl trimethylsilyl 
phosphite. ${ }^{22}$ During our research on azaheterocyclic phosphonates, ${ }^{23-26}$ we planned to use this phosphonylation reaction with $\alpha, \beta$-unsaturated imines.

\section{Addition to $\alpha, \beta$-Unsaturated Imines}

\subsection{Using dialkyl trimethylsilyl phosphites}

Initially, diethyl trimethylsilyl phosphite was prepared in situ, as shown previously. ${ }^{20}$ Upon treatment of imine 9a with the obtained phosphite reagent, the reaction mixture indeed consisted mainly of the 1,2-adduct $\mathbf{1 1}\left({ }^{31} \mathrm{P}-\mathrm{NMR}: \delta=24.4 \mathrm{ppm}\right)$ and residual starting material after 24 hours (Scheme 3). However, several small ${ }^{31}$ P-NMR signals were present and became more abundant upon prolonged reaction times. The minor peaks appeared as two doublets $(J=9.7 \mathrm{~Hz})$ next to two singlets and could be assigned to the double-addition product 10a (two diastereomers, ratio: 27:73) after its isolation in very low yield by column chromatography (Table 1). ${ }^{27}$<smiles>C(=C/c1ccccc1)\CCc1c[nH]c2ccccc12</smiles>

$9 a$

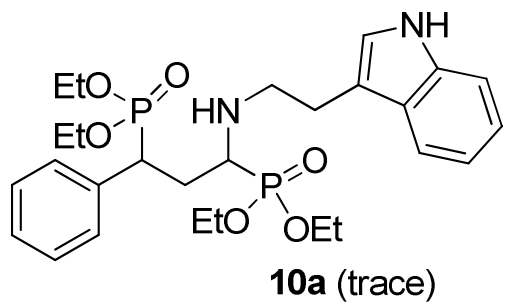

$\mathrm{HP}(\mathrm{O})(\mathrm{OEt})_{2}$, TMSCl, $\mathrm{Et}_{3} \mathrm{~N}, \mathrm{CH}_{2} \mathrm{Cl}_{2}, 20^{\circ} \mathrm{C}, 24 \mathrm{~h}$

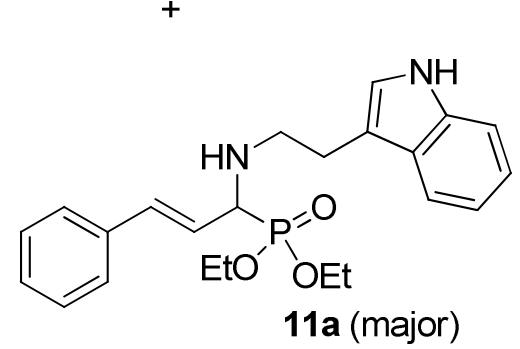

Scheme 3. The first observation of a tandem 1,4-1,2-addition of trimethylsilyl dialkyl phosphites.

The same type of product was obtained in increasing amounts, proportional to the steric bulk of the $\mathrm{N}$-substituent using imines 9b-f (Table 1). This observation nicely explained the decreasing yields of 1,2-adducts when more sterically hindered $N$-substituents were used in the original report. ${ }^{22}$ With a $N$-phenyl substituent, however, only 1,2-addition was observed.

These results prompted us to look for appropriate reaction conditions to achieve higher yields of the desired Glu bioisosteres 10. When the imine 9b was added to two equivalents of diethyl trimethylsilyl phosphite, prepared in situ, complete conversion of the imine into the 3-phosphonyl 1-aminoalkylphosphonate (PAP) 10b was achieved after 72 hours at reflux temperature. However, when the diethyl trimethylsilyl phosphite was filtered first to remove the triethylammonium salts, no reaction occurred at all when the imine was added. Also no reaction was observed on addition of 
$\mathrm{LiCl}$ or TMSCl, even though the latter was said to act as a catalyst in the reaction mechanism proposed by Afarinkia et al. ${ }^{20}$ Addition of $\mathrm{NH}_{4} \mathrm{Cl}$ led to approximately the same result as obtained before (complete conversion in 72 hours). Therefore, $\left(\mathrm{NH}_{4}\right)_{2} \mathrm{SO}_{4}$ was selected as a more acidic salt

Table 1. Substrate scope of the tandem addition using dialkyl trimethylsilyl phosphites

(10)

\footnotetext{
${ }^{\mathrm{a}}$ Yield after column chromatography or acid-base extraction.
} 
to replace the triethylammonium salts after filtration, thus leading to a remarkable acceleration of the reaction rate (complete conversion after 3 hours of reflux). Moreover, when diethyl trimethylsilyl phosphite was mixed with an imine in dry dichloromethane, the reaction proceeded violently upon addition of one equivalent of concentrated sulfuric acid to yield $\mathbf{1 0 b}$ as a single product in 30 minutes at room temperature. Also with other $\alpha, \beta$-unsaturated imines complete conversion into the corresponding PAP was observed. Diastereomeric ratios were determined from ${ }^{31} \mathrm{P}$ - and ${ }^{1} \mathrm{H}-\mathrm{NMR}$ integration measurements (Table 1).

The isolation of these bisphosphonates deserves some further attention. The polar nature of these compounds leads to significant losses upon chromatography. Where possible, extractive purification was preferred. A typical workup procedure consists of two consecutive extractions. After reaction the crude mixture was poured into a $3 \mathrm{M} \mathrm{HCl}$ solution and extracted thrice with diethyl ether in order to (hydrolyze and) remove excess phosphite. Diethyl ether was used to avoid substantial losses of protonated PAPs. Next, the aqueous phase was rendered basic using $3 \mathrm{M} \mathrm{NaOH}$ and extracted three times with dichloromethane, in order to remove any salts and acid. The combined organic layers were dried over $\mathrm{MgSO}_{4}$, filtered and concentrated in vacuo. In some cases subsequent column chromatography was needed.

In addition to $\mathrm{NH}_{4} \mathrm{Cl},\left(\mathrm{NH}_{4}\right)_{2} \mathrm{SO}_{4}$ and sulfuric acid, several other acidic media were evaluated as catalysts. While none of these proved to be as efficient as sulfuric acid, the most significant results of these experiments are shown in Table 2. Three types of zeolites were evaluated, LZ-Y20 (Catalytic activity $0.24 \mathrm{~mol} / \mathrm{kg}$; micropore volume $0.32 \mathrm{~mL} / \mathrm{g}), \mathrm{CBV} 3020 \mathrm{E}(0.54 \mathrm{~mol} / \mathrm{kg} ; 0.13$ $\mathrm{mL} / \mathrm{g}$ ) and CVB500 (1.5 mol/kg; n.a.). The LZ-Y20 zeolite efficiently catalyzes the tandem addition process, resulting in a conversion of $90 \%$ (entry 2). The isolated yield for this entry was $62 \%$, and as such the use of sulfuric acid is still preferred. Quite surprisingly, the other two zeolites tested catalyzed only the 1,2-addition and no PAP was detected.

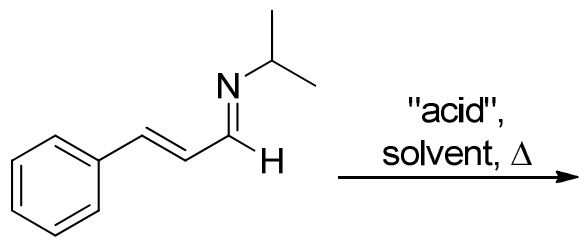

9d

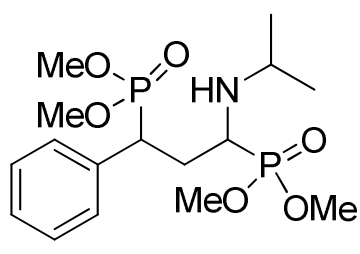

$10 \mathrm{e}$

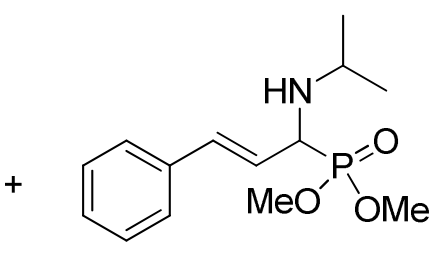

$11 \mathrm{e}$

Scheme 4. Evaluation of different acid catalysts.

The use of trifluoroethanol (TFE) as both solvent and proton source was relatively successful as well. A conversion of $75 \%$ could be obtained, but the isolated yield was disappointingly low at $45 \%$. Finally, polyphosphoric acid (PPA) was evaluated as a milder alternative to sulfuric acid (pKa 0.85 vs. -3 ), but only very low amounts of the desired PAPs were formed. 
Table 2. Conversion of aldimine 9d according to Scheme 4

\begin{tabular}{|c|c|c|c|c|c|}
\hline \multirow{2}{*}{ Entry } & \multirow{2}{*}{ Catalyst (equiv) } & \multirow{2}{*}{ Solvent } & \multirow{2}{*}{ Time (days) } & \multicolumn{2}{|c|}{ Conversion $(\%)^{\mathrm{a}}$} \\
\hline & & & & $10 \mathrm{e}$ & 11e \\
\hline 1 & LZ-Y120 (0.5) & $\mathrm{CH}_{2} \mathrm{Cl}_{2}$ & 7 & 31 & - \\
\hline 2 & LZ-Y120 (0.5) & $\mathrm{ClCH}_{2} \mathrm{CH}_{2} \mathrm{Cl}$ & 5 & 90 & - \\
\hline 3 & LZ-Y120 (0.5) & $\mathrm{CH}_{3} \mathrm{CN}$ & 7 & 73 & - \\
\hline 4 & CBV3020E (0.5) & $\mathrm{CH}_{2} \mathrm{Cl}_{2}$ & 6 & - & 33 \\
\hline 5 & CBV3020E (1.0) & $\mathrm{CH}_{2} \mathrm{Cl}_{2}$ & 4 & - & 12 \\
\hline 6 & CBV3020E (0.5) & $\mathrm{ClCH}_{2} \mathrm{CH}_{2} \mathrm{Cl}$ & 6 & - & 13 \\
\hline 7 & CBV3020E (0.5) & $\mathrm{CH}_{3} \mathrm{CN}$ & 6 & - & - \\
\hline 8 & CVB500 (0.5) & $\mathrm{CH}_{2} \mathrm{Cl}_{2}$ & 3 & - & 3 \\
\hline 9 & CVB500 (1.0) & $\mathrm{CH}_{2} \mathrm{Cl}_{2}$ & 4 & - & 28 \\
\hline 10 & CVB500 (0.5) & $\mathrm{ClCH}_{2} \mathrm{CH}_{2} \mathrm{Cl}$ & 4 & - & 32 \\
\hline 11 & CVB500 (0.5) & $\mathrm{CH}_{3} \mathrm{CN}$ & 4 & - & - \\
\hline 12 & - & TFE & 3 & 75 & - \\
\hline 13 & PPA (1.0) & $\mathrm{CH}_{2} \mathrm{Cl}_{2}$ & 4 & 2 & 18 \\
\hline 14 & PPA (2.0) & $\mathrm{CH}_{2} \mathrm{Cl}_{2}$ & 2 & 1 & 13 \\
\hline 15 & PPA (1.0) & $\mathrm{ClCH}_{2} \mathrm{CH}_{2} \mathrm{Cl}$ & 3 & 4 & 20 \\
\hline
\end{tabular}

${ }^{\mathrm{a}}$ Determined by ${ }^{31} \mathrm{P}-\mathrm{NMR}$ integration.

\subsection{Using trialkyl phosphites}

The above described unique reactivity of dialkyl trimethylsilyl phosphite toward $\alpha, \beta$-unsaturated imines 9 subsequently prompted us to evaluate the reactivity of other phosphorus nucleophiles. ${ }^{28}$ In particular, the resemblance of trialkyl phosphites to dialkyl trimethylsilyl phosphites, suggests these nucleophiles as potential tandem addition candidates. Both phosphite reagents occur in the highly nucleophilic $\sigma 3 \lambda 3$ form. Addition of trialkyl phosphite to $\alpha, \beta$-unsaturated imines 9 was previously reported to proceed with complete 1,4-regioselectivity when a steric nitrogen substituent $(t-\mathrm{Bu})$ was used by Teulade and Savignac. ${ }^{21}$ In their case, imine 9f was treated with 0.96 equivalents of triethyl phosphite in ethanol. A slight excess of formic acid (1.04 equiv) was added to dealkylate the intermediate phosphonium ion. However, when these reaction conditions were repeated with 1 equivalent of triethyl phosphite, using $i$-propylimine 9d as the substrate, a small amount of 3phosphonyl-1-aminophosphonate 10d could be detected in the crude reaction mixture after standard 
aqueous work-up and ${ }^{31} \mathrm{P}-\mathrm{NMR}$ analysis. When moving to an $N$-phenyl substituent, the 3phosphonyl-1-aminoalkylphosphonate $\mathbf{1 0 1}$ even becomes the major product next to a considerable amount of unreacted starting material 9 since only 1 equivalent of triethyl phosphite was added (Scheme 5).<smiles>[R]N=CC=C([R])[R]</smiles>

9f $\mathrm{R}^{1}=\mathrm{Ph} ; \mathrm{R}^{2}=\mathrm{H} ; \mathrm{R}^{3}=t-\mathrm{Bu}$

9d $\mathrm{R}^{1}=\mathrm{Ph} ; \mathrm{R}^{2}=\mathrm{H} ; \mathrm{R}^{3}=i-\mathrm{Pr}$

9l $\mathrm{R}^{1}=\mathrm{Ph} ; \mathrm{R}^{2}=\mathrm{H} ; \mathrm{R}^{3}=\mathrm{Ph}$

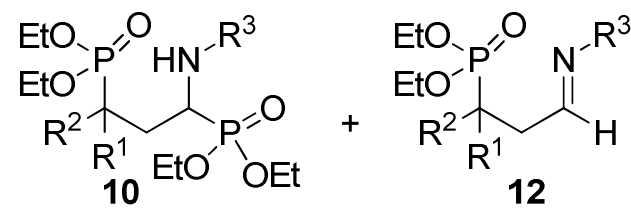

$10 f: 12 f=1: 99$

10d:12d = 5:95

10l: $12 \mathrm{l}=91: 9$

Scheme 5. The first observation of a tandem 1,4-1,2-addition of trialkyl phosphites.

These preliminar results prompted us to search for appropriate reaction conditions to achieve complete conversion of the imines 9 to the 3-phosphonyl-1-aminoalkylphosphonate 10. The reaction proceeded vigorously upon addition of 2 equivalents of formic acid to a mixture of 2 equivalents triethyl phosphite and the substrate 9 in ethanol. Complete conversion to the 3phosphonyl-1-aminoalkylphosphonate $\mathbf{1 0}$ was obtained in typically 30 minutes at room temperature. The generality of this method was shown by selecting different nitrogen substituents, both aromatic and aliphatic $\alpha, \beta$-unsaturated aldimines and different phosphorus nucleophiles (Table 3). When trimethyl phosphite $(\mathrm{R}=\mathrm{Me})$ was used, instead of triethyl phosphite, methanol was chosen as a solvent (instead of ethanol) to prevent transesterification. However, the reaction proceeded more slowly and more impurities were formed. Therefore, the solvent is probably an important factor influencing the reactivity of both nucleophiles.

The more sterically hindered $i$-Pr derivative $9 d$ required $24 \mathrm{~h}$ to achieve complete conversion, and the $t$-Bu-imine 9f only reacted in a 1,4-fashion (Table 3). This reactivity is opposite to the results obtained using dialkyl trimethylsilyl phosphite as a nucleophile. Using dialkyl trimethylsilyl phosphite, the highly steric $t$-Bu group is the best $N$-substituent to obtain double adducts, while phenyl, a less sterically hindered nitrogen substituent, resulted only in the 1,2-adducts. ${ }^{27}$ As was the case for the dialkyl trimethylsilyl phosphite tandem addition, ${ }^{27}$ the acid also plays a crucial role in the trialkyl phosphite addition. Next to the imine activation and enamine tautomerization, the acid (or its conjugated base) is required for dealkylation of the phosphonium intermediates (see below). From these experimental results, it was clear that both addition reactions of trialkyl phosphite or dialkyl trimethylsilyl phosphite to $\alpha, \beta$-unsaturated imines 9 proceed very fast in acidic media, yielding the corresponding diphosphonates $\mathbf{1 0}$ in high yields and purity. Both reactions proceed via a tandem 1,4-1,2-addition mechanism, which is also indicated by the occurrence of 1,4-adducts as intermediates (especially with highly steric demanding nitrogen substituents) and the similar diastereomeric ratios of the final products. The different influence of sterically hindered $N$ substituents however, indicates the involvement of differing reaction pathways or intermediates. 
Table 3. Substrate scope of the tandem addition using trialkyl phosphites

(1)

\footnotetext{
${ }^{\mathrm{a}}$ Yield after acid-base extraction; ${ }^{\mathrm{b}}$ Yield after column chromatography of the evaporated reaction mixture (product decomposes during acidic aqueous work-up); ${ }^{\mathrm{c}}$ Yield after acid-base extraction and additional column chromatography.
} 
In an attempt to eliminate the use of preformed aldimines, the possibility that the above described tandem 1,4-1,2-addition operates under typical Kabachnik-Fields-type, ${ }^{29-33}$ threecomponent reaction conditions were investigated. The method reported by Kudrimoto and Bommena was selected as a model. ${ }^{34}$ This method involves a solvent-free three-component reaction between an aldehyde, an amine, and a trialkyl phosphite, which was reported to yield exclusively $\alpha$ amino alkylphosphonates under the action of (bromodimethyl)sulfonium bromide $\left(\mathrm{Me}_{2} \mathrm{~S} . \mathrm{Br}_{2}\right)$, even when an $\alpha, \beta$-unsaturated aldehyde was used. However, when cinnamaldehyde was reacted with $i$ Pr-amine or aniline in the presence of 2 equivalents of trimethyl phosphite and 0.1 equivalent of $\mathrm{Me}_{2} \mathrm{~S}_{3} \mathrm{Br}_{2}$, small amounts of 3-phosphonyl-1-aminoalkylphosphonate 10d,m could be detected by ${ }^{31} \mathrm{P}-\mathrm{NMR}$ in the crude reaction mixture after standard aqueous work-up. Evaluating different timetemperature combinations, however, never resulted in complete conversion to the 3-phosphonyl-1aminoalkylphosphonate (maximum up to $60 \%$ in the reaction mixture). The catalysis of this reaction by (bromodimethyl)sulfonium bromide seems to be less efficient than the acid catalysis discussed above.

\subsection{Using tris(trimethylsilyl)phosphites}

The above described methods conveniently provide bisphosphonates from unsaturated aldimines. While the conversion of these phosphonates to the corresponding phosphonic acids is feasible using $\mathrm{TMSBr}$, this conversion is quite cumbersome. In order to obtain the phosphonic acids directly, we envisioned the use of a different $\sigma 3 \lambda 3$-phosphorus species, namely tris(trimethylsilyl)phosphite. Preliminary experiments soon showed the difficulty of using this reagent in the tandem addition process. Treatment with sulfuric acid resulted in its fast degradation to phosphonic acid. Also upon the use of triethylammonium chloride or formic acid, no addition products could be detected. It seemed that large amounts of sulfuric acid degraded the P-nucleophile, while other catalysts were insufficiently acidic to catalyse the desired tandem addition process. Eventually, the slow addition of subequimolar amounts of sulfuric acid provided a suitable solution and the silylated precursors of bisphosphonates 10t-y (Scheme 6) could be detected. A subsequent quench with methanol provides the corresponding phosphonic acids.

Isolation of the phosphonic acids was performed by precipitation in diethyl ether or, when the resulting purity was unsatisfactory, chromatography over Dowex. A range of substrates was evaluated, as shown in Table 4. Again the nitrogen substituent was of utmost importance. The use of sterically hindered $i$-propyl or $t$-butyl groups proved to be the best, leading to the formation of PAPs in reasonable to good yields. When using allyl, benzyl or phenyl groups however, only 1,2addition could be observed. These observations are consistent with those when using trimethylsilyl dialkyl phosphites. In general, however, the use of tris(trimethylsilyl)phosphite proved to be less straightforward and limited to very specific substrates. 


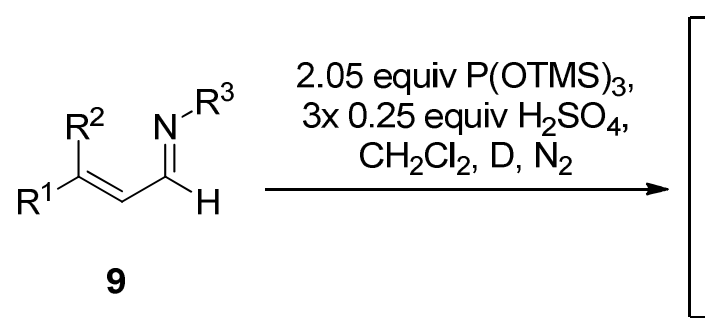

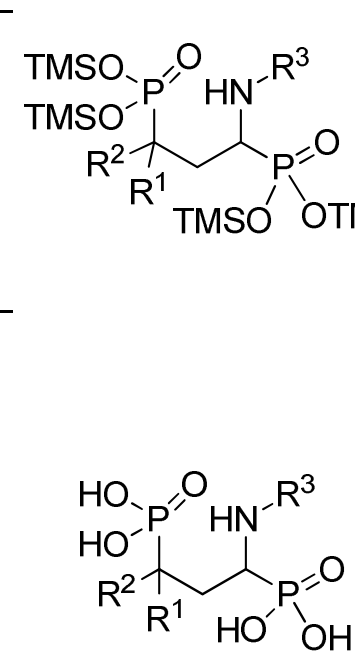

$10 t-y$<smiles>[R]NC(C=C([R])[R])P(=O)(OC)O[Na]</smiles>

$\mathrm{MeOH}$

$\checkmark$

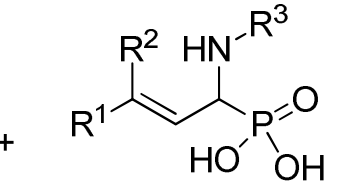

11t-y

Scheme 6. Tandem addition using tris(trimethylsilyl) phosphite.

Table 4. Substrate scope of the tandem addition using tris(trimethylsilyl) phosphites

\begin{tabular}{|c|c|c|c|c|c|c|}
\hline \multirow{2}{*}{ Entry } & \multirow{2}{*}{ Substrate } & & \multirow{2}{*}{ Time (hours) } & \multicolumn{2}{|c|}{ Conversion $(\%)^{\mathrm{a}}$} & \multirow{2}{*}{ d.r. } \\
\hline & & & & 10 & 11 & \\
\hline $\mathrm{t}$ & & 9d & 30 & $83\left(61^{b}\right)$ & $14\left(8^{\mathrm{b}}\right)$ & $28: 72$ \\
\hline $\mathrm{u}$ & & 9f & 52 & $95\left(46^{\mathrm{b}}\right)$ & - & $49: 51$ \\
\hline $\mathrm{v}$ & & $9 b$ & 65 & - & $58\left(43^{c}\right)$ & - \\
\hline $\mathrm{W}$ & & 91 & 65 & - & $46(0)$ & - \\
\hline $\mathrm{x}$ & & $9 n$ & 64 & - & $93(0)$ & - \\
\hline
\end{tabular}


Table 4. Continued

\begin{tabular}{|c|c|c|c|c|c|c|}
\hline \multirow{2}{*}{ Entry } & \multirow{2}{*}{ Substrate } & & \multirow{2}{*}{ Time (hours) } & \multicolumn{2}{|c|}{ Conversion $(\%)^{\mathrm{a}}$} & \multirow{2}{*}{ d.r. } \\
\hline & & & & 10 & 11 & \\
\hline $\mathrm{y}$ & & $9 y$ & 70 & $40\left(0^{\mathrm{d}}\right)$ & $36\left(0^{\mathrm{d}}\right)$ & $25: 75$ \\
\hline
\end{tabular}

${ }^{\mathrm{a}}$ Conversion based on ${ }^{31} \mathrm{P}-\mathrm{NMR}$ and ${ }^{1} \mathrm{H}-\mathrm{NMR}$ integrations, isolated yield indicated in parentheses; byield after column chromatography over Dowex; ${ }^{c}$ yield after recrystallization in $\mathrm{Et}_{2} \mathrm{O}$; ${ }^{\mathrm{d}}$ no separation using Dowex.

\subsection{Mechanistic implications}

To elucidate the reaction pathways involved in the addition of dialkyl trimethylsilyl and trialkyl phosphites to the $\alpha, \beta$-unsaturated imines, the reaction was monitored by ${ }^{31} \mathrm{P}$-NMR spectroscopy. As the reaction of imine $9 \mathrm{~b}$ with diethyl trimethylsilyl phosphite catalyzed by sulfuric acid proceeds too rapidly to detect any reaction intermediates, triethylammonium chloride was selected as a less potent catalyst to monitor the reaction as a function of time. Rapid disappearance of $\mathbf{9 b}$ was observed, whereas the amount of the 1,2-adduct grew accordingly to a maximum. The PAP 10b was formed more slowly, however, finally becoming the only end product of the reaction (see Figure 1). As a consequence of the fast but reversible 1,2-addition of dialkyl trimethylsilyl phosphite to aldimines, this reaction was erroneously reported earlier to proceed with complete 1,2regioselectivity. ${ }^{22}$

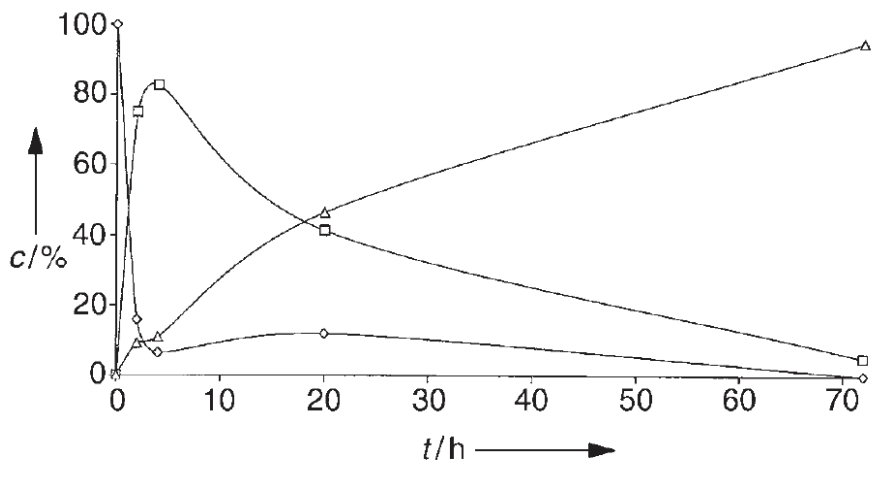

Figure 1. Composition of the reaction mixture during the reaction of $9 \mathbf{b}(\diamond)$ with $\mathrm{P}(\mathrm{OEt})_{2} \mathrm{OTMS}$ in the presence of $\mathrm{HNEt}_{3} \mathrm{Cl}$, measured by NMR. The 1,2-adduct 11b $(\square)$ appears as an intermediate while the PAP 10b $(\triangle)$ is the final product. 


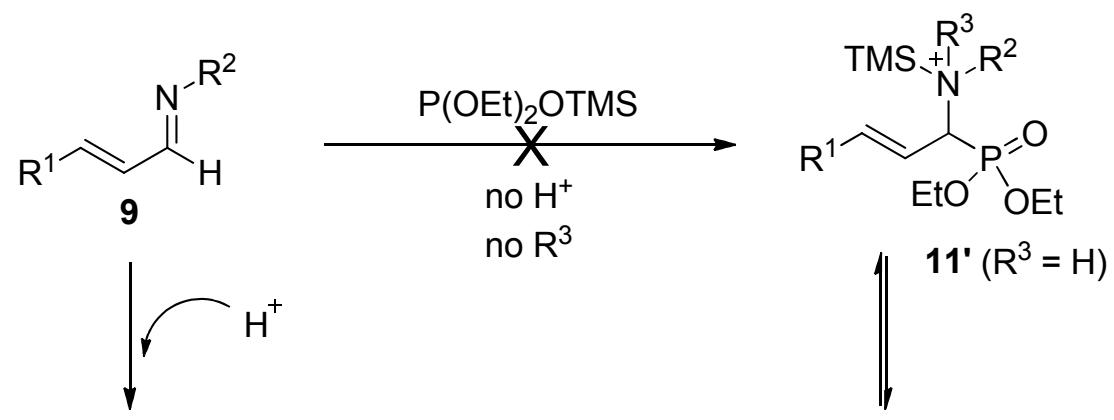

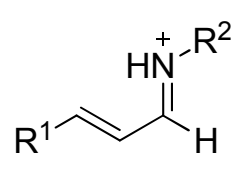

13

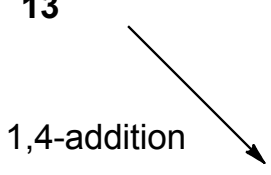

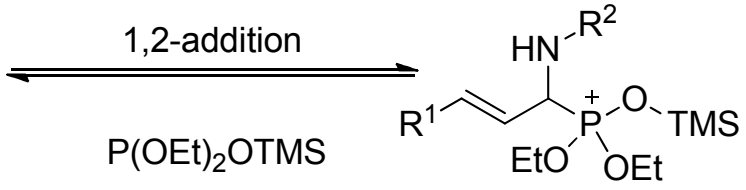

14

TMS
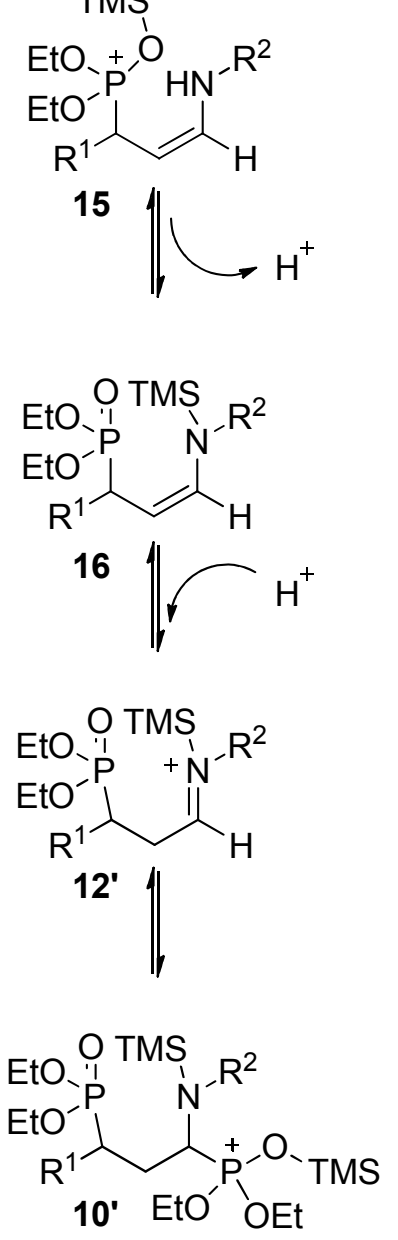

Scheme 7. Suggested reaction mechanism of tandem addition using silylated phosphites. 
This behavior suggests that the imine is protonated first by the acid and becomes activated towards nucleophilic attack of the dialkyl trimethylsilyl phosphite (Scheme 7). 1,2-Addition is clearly the fastest reaction pathway and the $N$-trimethylsilyl 1-aminoalkylphosphonate (11') is formed after nucleophilic attack of the nitrogen atom at the trimethylsilyl group of phosphonium salt 14.

These three steps all occur in an equilibrium which was demonstrated in a separate experiment (Scheme 8). When dimethyl (1-amino-1-phenylmethyl)phosphonate (17) was $N$-silylated using TMSCl and subsequently treated with a large excess of diethyl trimethylsilyl phosphite, diethyl phosphonate 18 was mainly recovered along with small amounts of $\mathbf{1 7}$. When the same experiment was repeated without silylation and using diethyl phosphite, no exchange at all occurred. This clearly demonstrated the reversibility of the reaction (Scheme $7, \mathbf{9} \rightleftharpoons \mathbf{1 1}$ ') and the need for the generation of a positively charged phosphonium group to increase its leaving-group capacity.

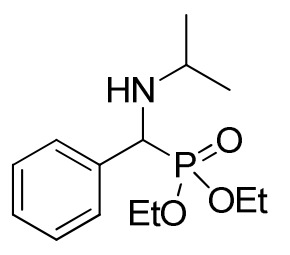

18

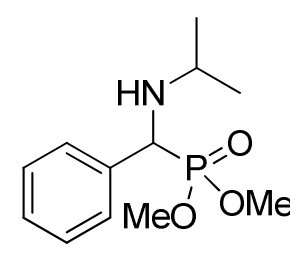

17
1. TMSCI 2. $\mathrm{P}(\mathrm{OEt})_{2} \mathrm{OTMS}$

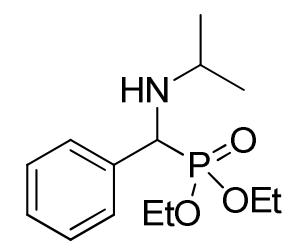

18

Scheme 8. Phosphonate exchange through silylation.

The initial equilibrium allows two further routes to the PAP 10' (Scheme 7). The first is complete reversion into the iminium salt followed by a slow 1,4-addition, whereas the second starts with an $\mathrm{S}_{\mathrm{N}}$ substitution of the phosphonium group. Both routes yield the same intermediate enamine 15, which subsequently isomerizes to the enamine 16. A final 1,2-addition then yields PAP 10'. However, the suggested intermediates $\mathbf{1 5}$ and 16 in this reaction mechanism (Scheme 7), were never observed. Furthermore, the proposed reaction mechanisms require an external proton source, as one equivalent of protons is incorporated in the final product 10. Therefore, an experiment was performed using only 0.1 equivalents of sulfuric acid together with 2.0 equivalents of $\mathrm{P}(\mathrm{OEt})_{2} \mathrm{OTMS}$. The reaction proceeded very sluggishly under these conditions, and the formation of $\mathbf{1 0}$ was stopped completely after 3-4 h as expected. From that point, the concentration of $\mathbf{1 5}$ started to increase $\left({ }^{31} \mathrm{P}-\mathrm{NMR}: \delta=\sim 27 \mathrm{ppm}\right.$ in the reaction medium), while the rest of the imine 9 was slowly consumed (Figure 2). From this evolution of intermediates as a function of the reaction time (Figure 2), it is clear that the 1,2-adduct 11' is not a real intermediate of the PAP formation. After the initial fast 1,2-adduct formation (which can also be noticed in Figure 1), further 1,2-additions are blocked by the absence of protons. The 1,4-addition on the other hand continues to proceed slowly. 


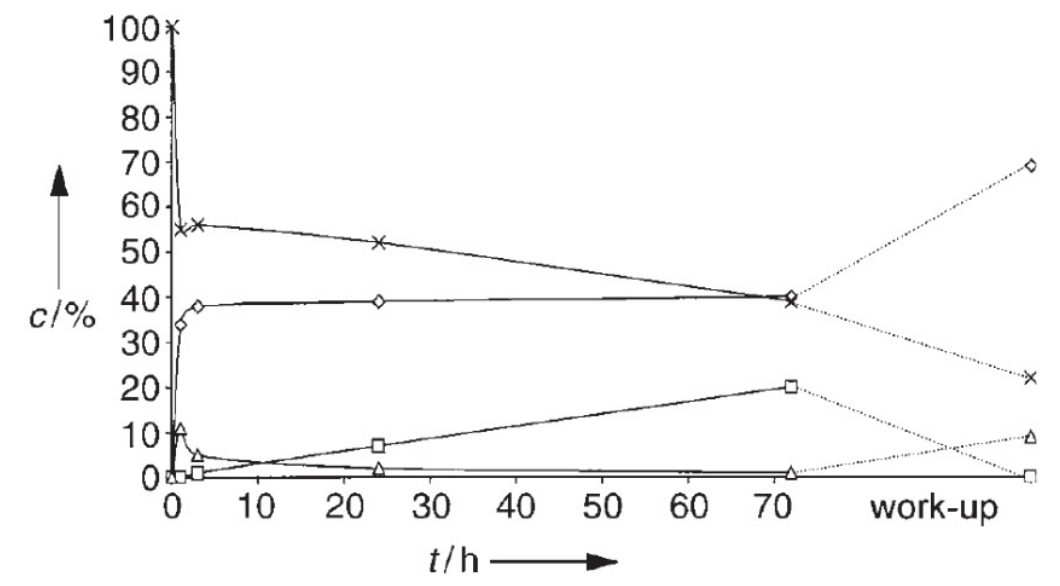

Figure 2. Composition of the reaction mixture during reaction of $9 \mathbf{d}(\times)$ with $\mathrm{P}(\mathrm{OEt})_{2} \mathrm{OTMS}$ in the presence of 0.1 equivalents of $\mathrm{H}_{2} \mathrm{SO}_{4}$, measured by NMR spectroscopy. Only a small amount of 1,2-adduct 11d $(\triangle)$ is formed, whereas PAP 10d $(\diamond)$ is formed very quickly. When the reaction stops due to a lack of protons, the concentration of intermediate enamine $16(\square)$ increases.

Furthermore, the observation that a considerably higher reaction rate results for imines bearing more sterically hindered $\mathrm{N}$-substituents $(t-\mathrm{Bu}>i-\mathrm{Pr}>\mathrm{Bn}>>\mathrm{Ph})$ is in favor of the tandem addition, as the 1,2-addition should be slowed down by the steric bulk. One case of a double addition, which also proceeded in a 1,4-1,2- tandem fashion has been reported for ketene silyl acetal addition to $\alpha, \beta$ unsaturated imines. ${ }^{35}$

In the case of trialkyl phosphite, the situation is slightly different and the 1,4-addition is clearly favored. No 1,2-adduct appears in the reaction mixture. The 1,4-adduct is the sole reaction intermediate or even the end product when subsequent 1,2-addition is blocked (e.g., due to steric hindrance). The origin of this differing evolution of reaction intermediates remains subject to discussion. From these results, one could conclude that a trialkyl phosphite is more sterically hindered in this type of reaction as compared to a dialkyl trimethylsilyl phosphite. This is quite surprising at first sight as one alkyl group is interchanged for a larger TMS group. A possible explanation for this unexpected behavior of dialkyl trimethylsilyl phosphite could also be found in the reaction mechanism of dialkyl trimethylsilyl phosphite additions described in literature. ${ }^{36}$ In this mechanism, coordination of the nitrogen lone pair with the silicon atom is suggested, which brings the (bulky) nucleophile in close proximity of the electrophilic center. Because of the presence of both a nucleophilic and an electrophilic center in the silylated phosphite, the subsequent transformation would then occur via a classical "push-pull" mechanism (Scheme 9) and is accelerated. However, the impressive rate increase upon acidification suggests protonation of the imine, which reduces the strength of this type of silyl complexation. 


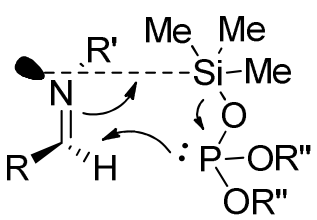

Scheme 9. Push-pull mechanism.

In this respect, it is interesting to note that when 1,2-adducts are observed, they are observed as a phosphonate and not as a phosphonium species. This suggests that, while reversible, $O$ - to $N$ - silyl transfer is a fast and near quantitative process. The $N$-silylated aminophosphonate 11' (Scheme 10) can therefore be regarded as a resting state, while its phosphonium counterpart $\mathbf{1 4}$ is a highly reactive intermediate. It was shown on several occasions in literature that this type of intramolecular phosphonium to phosphonate conversion is disfavoured for trialkyl phosphites. ${ }^{36}$ In fact, when aliphatic aldehydes are heated in the presence of trialkyl phosphites, only up to $40 \%$ of the $\alpha$-alkoxy phosphonate has been reported, ${ }^{37-38}$ which most likely originates from an intermolecular alkyl transfer. ${ }^{39} \mathrm{O}$ - to $\mathrm{N}$ - alkyl transfer does not occur, and aminophosphonate formation relies on the presence of other dealkylation agents.

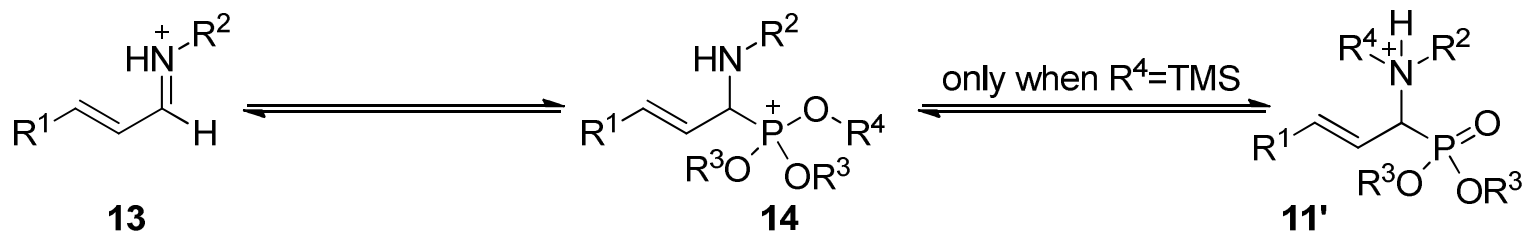

Scheme 10. Only silylated phosphites facilitate intramolecular $O$ - to $N$-transfer.

As such, it is very well possible that the initial 1,2-addition of trialkyl phosphites occurs in a similar fashion as for silylated phosphonates, but is blocked at the intermediate reactive phosphonium species which readily reverts to the imine. In fact, trialkyl phosphites have been used on several occasions to perform 1,2-additions on $\alpha, \beta$-unsaturated imines and $\alpha$-aminophosphonates can be isolated in the presence of dealkylating agents. ${ }^{30,40-46}$

Taking these facts in account, the initial steps of the tandem addition process are depicted in more detail in Scheme 11. Under the strongly acidic conditions, the imine is protonated in a near quantitative manner $\left(\mathrm{k}_{2}>>\mathrm{k}_{1}\right)$. Regardless of which type of phosphite is used, the iminium species can be converted to phosphonium 14. However, this intermediate is highly unstable and it readily reverts to the iminium. Here, $\mathrm{k}_{4}$ largely exceeds $\mathrm{k}_{3}$ and no phosphonium intermediates can be observed. However, when $\mathrm{R}^{4}$ is a TMS group, $O$ - to $N$ - transfer will be favored over the elimination of the phosphite $\left(\mathrm{k}_{6}>>\mathrm{k}_{4}\right)$, leading to the conversion of iminium $\mathbf{1 3}$ to 11', which is not easily recycled through the phosphonium species $\left(\mathrm{k}_{6}>>\mathrm{k}_{5}\right)$. This results in an overall conversion of imine 9 to the 1,2-addition product with a reaction rate that exceeds that of the 1,4-addition. When $\mathrm{R}^{4}$ is an alkyl group on the other hand, $\mathrm{k}_{6}$ will be at or near zero, and a further 1,4-addition will be the predominant process. 
While the 1,4-addition is a relatively smooth process, only limited amounts of substrate (imine) are available for the 1,4-addition when using silylated phosphites, causing it to be the ratedetermining step. Suppressing the formation of 11', by increasing the steric demands of $\mathrm{R}^{2}$ (lowering $\mathrm{k}_{4}$ and $\mathrm{k}_{6}$ and increasing $\mathrm{k}_{5}$ ) accelerates the formation of the desired PAPs.

When trialkyl phosphite is used, no 1,2-adduct formation is observed. 1,4-Addition proceeds through a classical nucleophilic attack. The final 1,2-addition is now the rate-determining step, which is disfavored by sterically hindered nitrogen substituents. Increasing the steric demand of $\mathrm{R}^{2}$ slows the formation of the desired PAPs down, which is also the reason Teulade and Savignac only reported 1,4-addition to the steric $t$-Bu-imines. ${ }^{21}$ These exceptional reaction kinetics, rather than simply steric differences, explain the opposite reactivity order for both reagents.

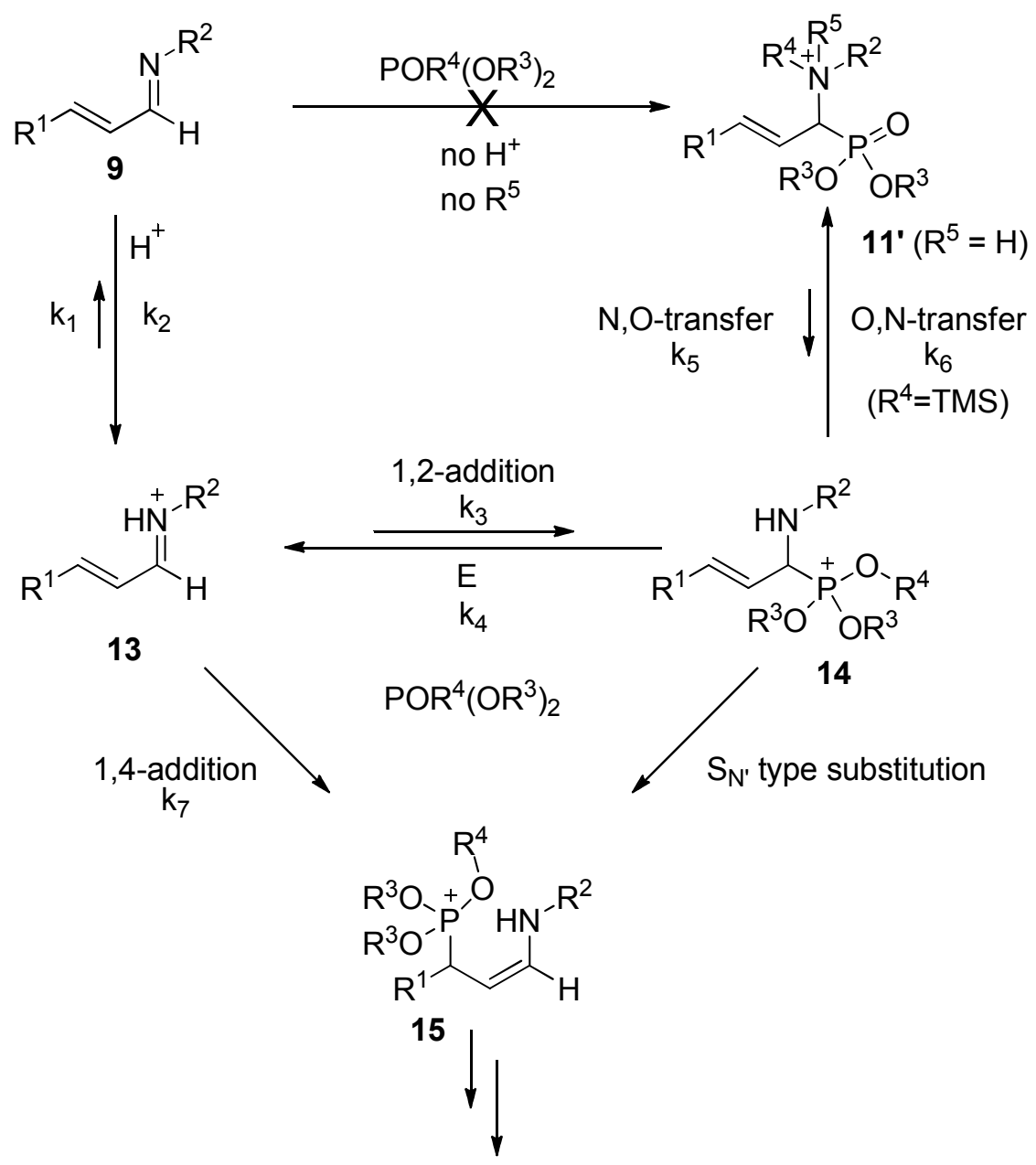

Scheme 11. Unified reaction mechanism for alkyl and silylated phosphites.

\section{Addition to $\alpha, \beta$-Unsaturated Hydrazones}

In continuation of the tandem 1,4-1,2-addition reactions of phosphites to $\alpha, \beta$-unsaturated imines, we next evaluated hydrazones and oximes as substrates. ${ }^{47}$ 
Hydrazones were expected to be less reactive toward nucleophilic attack compared to imines, as the second hydrazone nitrogen atom increases electron density on the electrophilic hydrazone carbon. Hydrazones were synthesized in excellent yields from $\alpha, \beta$-unsaturated aldehydes and hydrazines or hydrazides in methanol at $0{ }^{\circ} \mathrm{C}$. Next, diphosphonylation was evaluated using the two different phosphorus nucleophiles, i.e. dimethyl trimethylsilyl phosphite $\left(\mathrm{P}(\mathrm{OMe})_{2} \mathrm{OTMS}\right)$ and triethyl phosphite $\left(\mathrm{P}(\mathrm{OEt})_{3}\right)$ as depicted in Scheme 12.
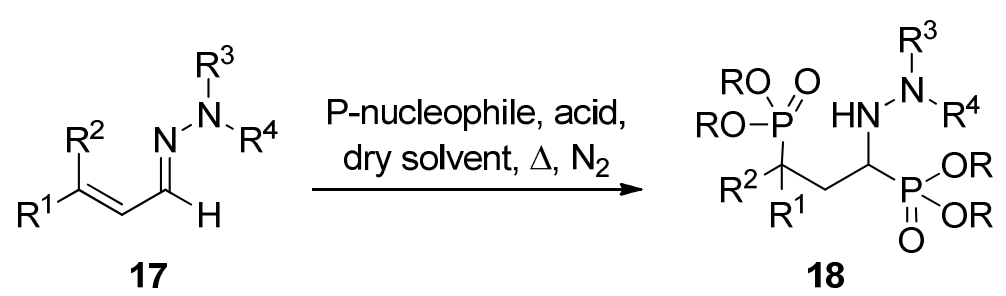

Scheme 12. Tandem 1,4-1,2-addition of phosphites to $\alpha, \beta$-unsaturated hydrazones.

Addition reactions with silylated phosphite were performed in refluxing dry dichloromethane under $\mathrm{N}_{2}$-atmosphere and were monitored using ${ }^{31} \mathrm{P}$-NMR. Conversion was much slower than it was in the case with $\alpha, \beta$-unsaturated imines and upon addition of $\mathrm{H}_{2} \mathrm{SO}_{4}$ no vigorous boiling of the solvent took place. Results are depicted in Table 5.

Table 5. Substrate scope of the tandem addition using dimethyl trimethylsilyl phosphite (DMPTMS) to $\alpha, \beta$-unsaturated hydrazones

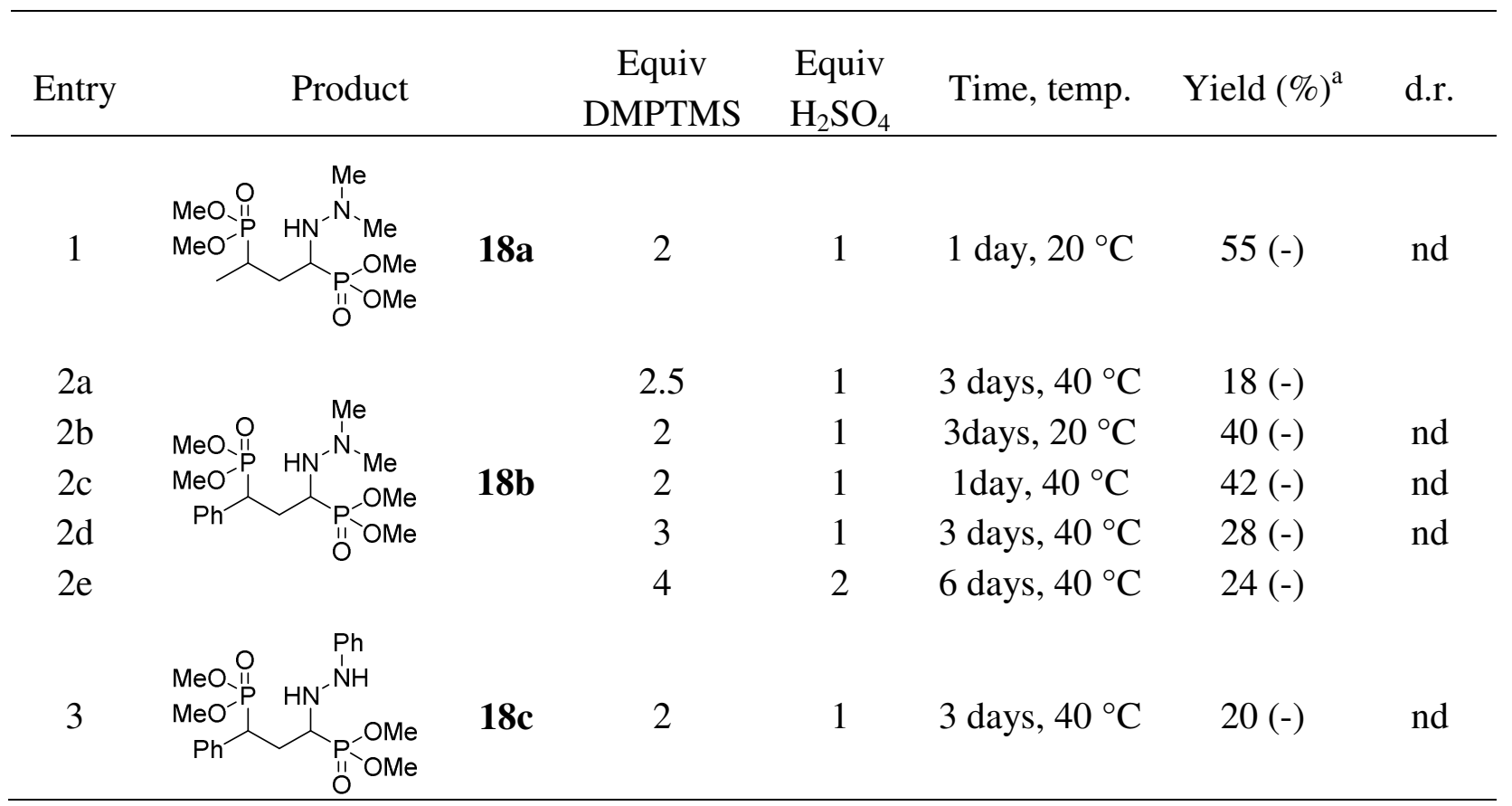


Table 5. Continued

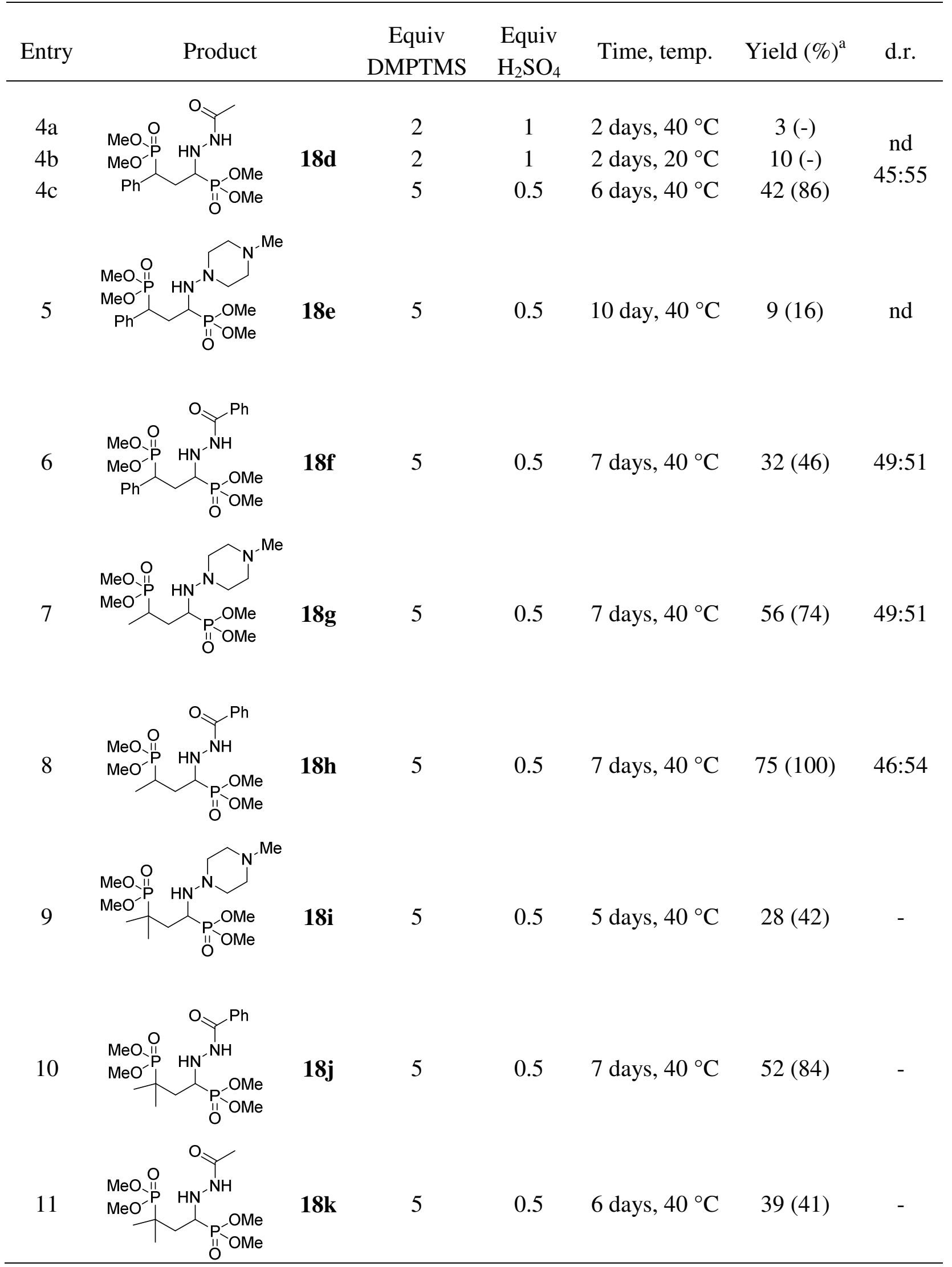


Table 5. Continued

\begin{tabular}{llcccccc}
\hline Entry & Product & $\begin{array}{c}\text { Equiv } \\
\text { DMPTMS }\end{array}$ & $\begin{array}{c}\text { Equiv } \\
\mathrm{H}_{2} \mathrm{SO}_{4}\end{array}$ & Time, temp. & Yield (\%) & d.r. \\
\hline 12 & $\mathbf{1 8 1}$ & 5 & 0.5 & 7 days, $40{ }^{\circ} \mathrm{C}$ & $19(35)$ & $38: 62$ \\
\hline
\end{tabular}

${ }^{a}$ Yield after acid-base extraction and subsequent column chromatography, conversion as determined by ${ }^{31} \mathrm{P}-\mathrm{NMR}$ is indicated in parentheses.

The products obtained contain two stereocenters and consequently exist as a mixture of diastereomers (a minor $(\mathrm{m})$ and a major $(\mathrm{M})$ component). This is visible in the ${ }^{31} \mathrm{P}-\mathrm{NMR}$ spectrum as two doublets for one diastereomer, in which coupling between both phosphorus atoms is visible, and two singlets for the other diastereomer, where no, or only a very small coupling constant is visible between both phosphorus atoms. Integration of these signals furnishes the ratio in which both diastereomers are present. No specific diastereoselectivity is present as most ratios are around 50:50.

Some trends can be deduced from these observations. The more steric hindrance is present at the 4-position (dimethyl > isopropyl > methyl > phenyl), the lower the isolated yield and the longer reaction times necessary. This added bulk slows down the initial 1,4-addition of the tandem reaction. When no bulky groups are present on the substituted nitrogen atom, 1,2-addition easily takes place which results in monoaddition and lower yields. In general, the low isolated yields are due to difficulties during work-up. An acid-base extraction is required to remove the excess phosphite and sulfuric acid, which accounts for losses of product. After the acid-base extraction, a supplementary chromatographic step is necessary to obtain analytically pure products. These hydrazine bisphosphonates display a great affinity for silica, again leading to significant losses of product.

Overall yields obtained using $\mathrm{P}(\mathrm{OMe})_{2} \mathrm{OTMS}$ were unsatisfactory and thus triethyl phosphite was evaluated as the alternative phosphorus nucleophile. As stated above, previous research had revealed that the use of triethyl phosphite in ethanol gives better results than trimethyl phosphite in methanol. $^{28}$

Several substrates and reaction conditions were evaluated, giving rise to some important conclusions. The highest conversions are achieved upon the use of 5 equivalents $\mathrm{P}(\mathrm{OEt})_{3}$ and 5 equivalents formic acid. When smaller amounts of phosphite were utilized, e.g. 2 equivalents, yields 
were below 5\%. Furthermore, upon addition of only 1 equivalent of formic acid, the yields were much lower as compared to the use of an excess of 5 equivalents.

More specifically in the case of hydrazones derived from 1-amino-4-methylpiperazine, when only equimolar amounts of acid are added, the more basic piperazine nitrogen atom is protonated and the substrate is not suitably activated. When an excess of acid is used all nitrogen atoms are protonated including the desired hydrazone nitrogen, leading to increased yields. Application of even more acid on the other hand is counterproductive and leads to dealkylation of $\mathrm{P}(\mathrm{OEt})_{3}$ with formation of diethyl phosphite. The addition of triethyl phosphite to hydrazones $\mathbf{1 7}$ was monitored by ${ }^{31} \mathrm{P}-\mathrm{NMR}$ and results are shown in Table 6.

Table 6. Substrate scope of the tandem addition using trimethylphosphite to $\alpha, \beta$-unsaturated hydrazones

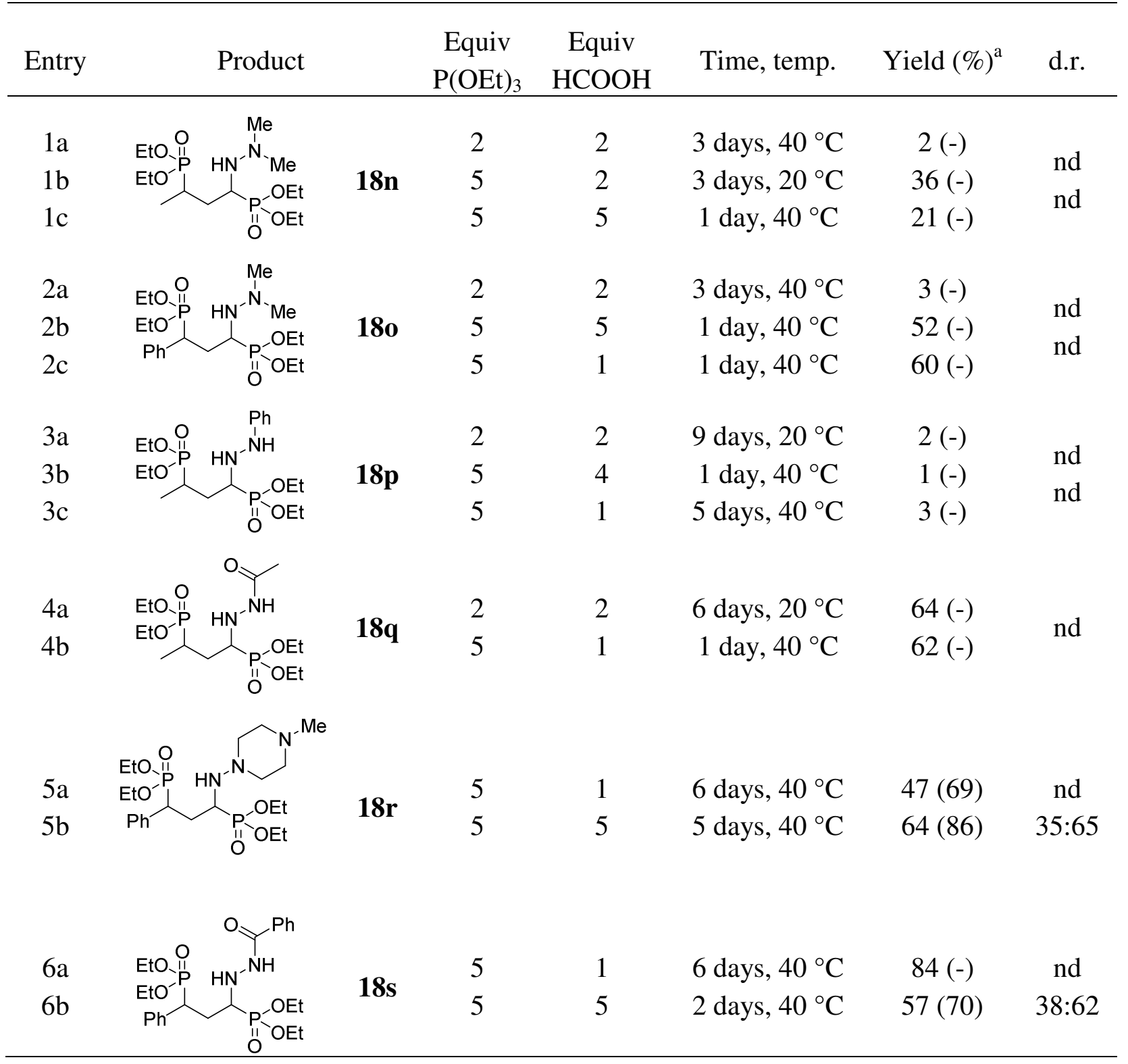


Table 6. Continued

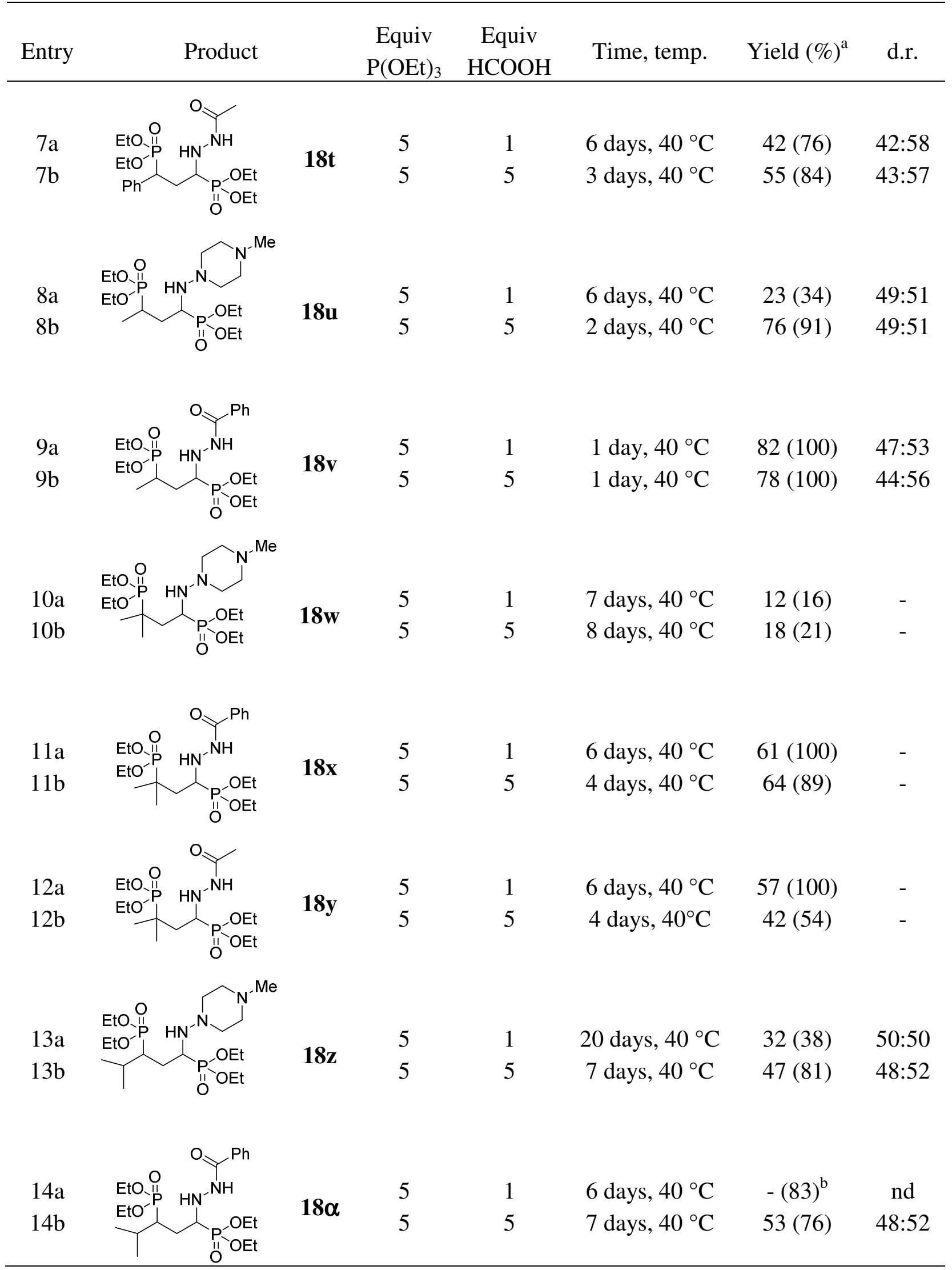


Table 6. Continued

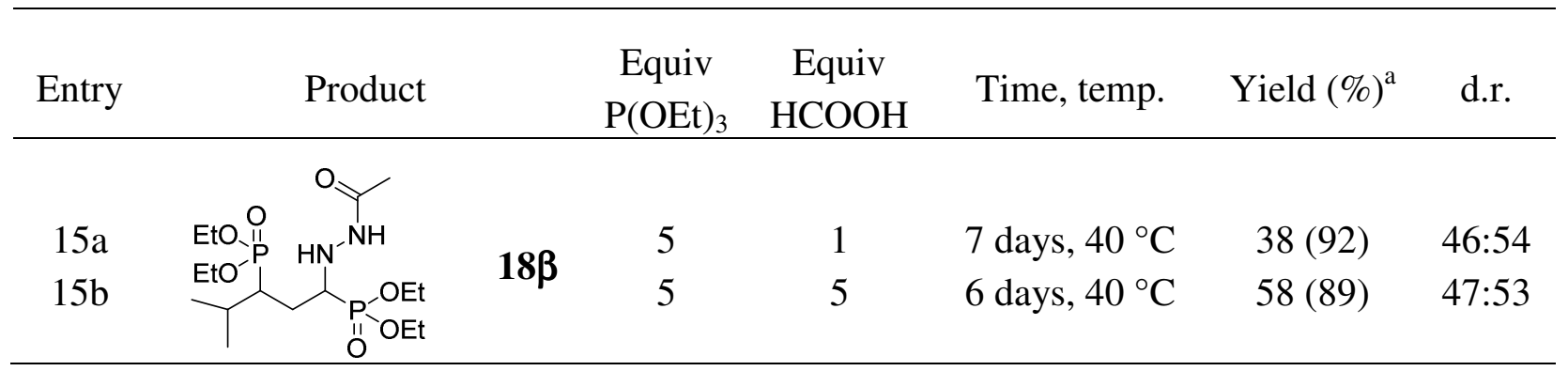

a Yield after acid-base extraction and subsequent column chromatography, conversion as determined by ${ }^{31} \mathrm{P}-\mathrm{NMR}$ is indicated in parentheses; ${ }^{\mathrm{b}}$ bisphosphonate in first organic phase, no recrystallization possible.

Conversions using triethyl phosphite as the nucleophile are usually better than those using silylated phosphite. The degree and nature of substitution on these substrates largely determines reaction time, as was the case with silylated phosphite. When bulky groups are present on the 4position, initial 1,4-addition is slower and complete conversion is much slower (compare entries 9a and 14a). In the absence of bulky groups on the hydrazone 1,2-addition was faster than 1,4-addition. Derivatives with a phenyl substituent on the 4-position display lower yields, most likely due to conjugation of the aromatic ring to the unsaturated system. Aside from steric hindrance, electron density on the $\mathrm{C}=\mathrm{N}$ carbon atom plays a major role. Substrates derived from 1-amino-4methylpiperazine display a lower reactivity due to increased electron density on the reactive center, impeding 1,2-addition. Derivatives with electron withdrawing amide functions undergo 1,2-addition more readily, resulting in shorter reaction times and higher conversions. However, these observations are not in all cases significant.

In an attempt to increase isolated yields, different work-up procedures were evaluated. Performing column chromatography immediately after the reaction without any prior work-up is not suitable, due to the excess triethyl phosphite still present. An acid-base extraction with dichloromethane and $3 \mathrm{M} \mathrm{HCl}$, followed by lyophilization was attempted, but no solids were obtained after freeze drying. This is due to the highly hygroscopic nature of these bisphosphonates. Only water was visible in the ${ }^{1} \mathrm{H}-\mathrm{NMR}$ spectrum. Therefore, the sequence of acid-base extraction and column chromatography, as described when using $\mathrm{P}(\mathrm{OMe})_{2} \mathrm{OTMS}$, was still preferred.

\section{Addition to $\alpha, \beta$-Unsaturated Oximes}

Next, oximes were evaluated as substrates for the tandem 1,4-1,2-addition reaction. The desired oximes were prepared according to literature procedures, in 83 and $90 \%$ yield respectively (Scheme 13). ${ }^{48-49}$ Both the $(E)$ - and $(Z)$-isomers were obtained, with the $(Z)$-isomer slowly converting to the (E)-configuration. 


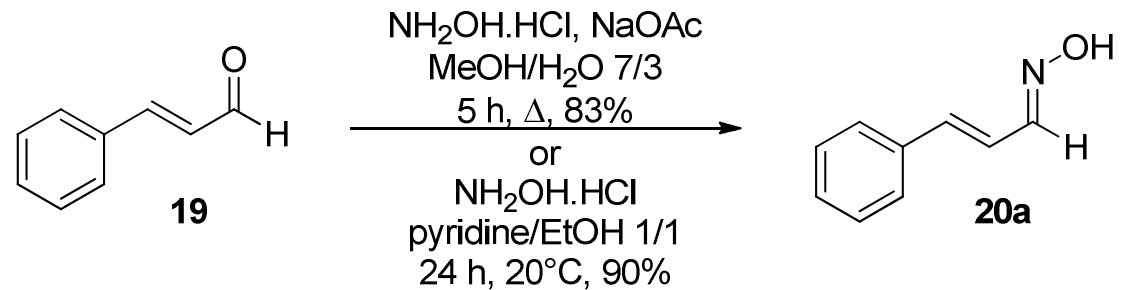

Scheme 13. Synthesis of oximes from cinnamaldehyde using two literature procedures.

Furthermore, the corresponding $O$-benzyl oxime was prepared from cinnamaldehyde and $O$ benzylhydroxylamine hydrochloride in dichloromethane with $\mathrm{MgSO}_{4}$ and $\mathrm{Et}_{3} \mathrm{~N}$. An attempt to recrystallize was unsuccessful and column chromatography was necessary for purification of the target oxime, unfortunately leading to only $10 \%$ yield.

Cinnamaldehyde oxime was subjected to similar reaction conditions as the hydrazones to induce tandem 1,4-1,2-addition with silylated phosphite (Scheme 14). Reaction with $\mathrm{P}(\mathrm{OMe})_{2} \mathrm{OTMS}$ in the presence of sulfuric acid did not succeed and only hydrolysis of the nucleophile to dimethyl phosphite was observed. To exclude the influence of the free hydroxyl function of the oxime, the corresponding $O$-benzyl oxime was evaluated as substrate. However, tandem addition did not proceed, even upon refluxing for several days, and the silylated phosphite was again hydrolyzed to dimethyl phosphite, albeit much slower.

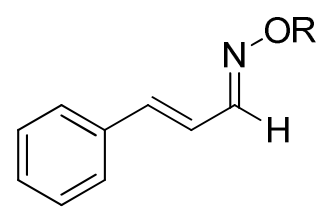

20a $(\mathrm{R}=\mathrm{H})$

$20 b(R=B n)$

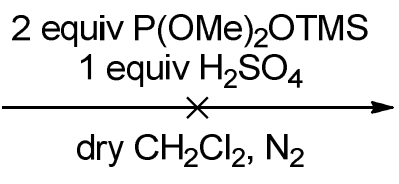

dry $\mathrm{CH}_{2} \mathrm{Cl}_{2}, \mathrm{~N}_{2}$

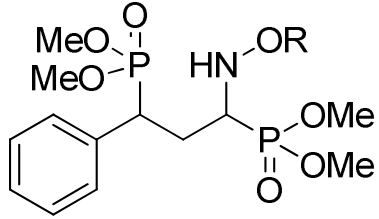

21a $(\mathrm{R}=\mathrm{H})$

21b $(\mathrm{R}=\mathrm{Bn})$

Scheme 14. Attempted tandem addition of silylated phosphite to $\alpha, \beta$-unsaturated oximes.

Next, the addition of triethyl phosphite was evaluated under similar conditions as for the hydrazones. After 4 days, only diethyl phosphite and starting material were present. Again, this may be attributed to hydrolysis. The $O$-benzyl oxime was utilized as well, but the result was similar to using the unprotected oxime, even though the hydrolysis of triethyl phosphite proceeded more slowly.

\section{Diphosphonylation of Aromatic Heterocycles}

At this point, we had shown that both silylated dialkyl phosphite and trialkyl phosphite can be used to perform a tandem 1,4-1,2-addition to $\alpha, \beta$-unsaturated aldimines and hydrazones. On the other hand, $\alpha, \beta$-unsaturated oximes are not susceptible to the tandem 1,4-1,2-addition. In continuing our 
efforts to broaden the scope of this reaction, we evaluated more challenging substrates, in the form of aromatically stabilised $\alpha, \beta$-unsaturated imines.

\subsection{Quinolines}

The first part of the research focussed on the use of triethyl phosphite in ethanol, as our experiments on the hydrazones had shown this to be the most robust reagent combination. The quinoline was dissolved in absolute EtOH and triethyl phosphite (2 equiv) was added together with formic acid (1 equiv). Despite several attempts, no addition was observed, both at room temperature and under reflux conditions. ${ }^{50}$

Subsequently, a silylated dialkyl phosphite was used as phosphorus nucleophile. In this procedure, the quinoline was dissolved in dry $\mathrm{CH}_{2} \mathrm{Cl}_{2}$ and a silylated phosphite (2 to 3 equiv, depending on the substrate) and $\mathrm{H}_{2} \mathrm{SO}_{4}$ (0.5 equiv) were added. The mixture was stirred at room temperature or heated to reflux. ${ }^{31} \mathrm{P}-\mathrm{NMR}$ analysis revealed that the addition took place and that it is indeed possible to disrupt the aromatic stabilisation. However, the quinolines reacted much slower compared to the imines due to the aromatic character of these heterocycles. Scheme 15 gives a proposed reaction mechanism for the tandem 1,4-1,2-addition of silylated dimethyl phosphite to quinoline. The suggested intermediates in this mechanism could not be isolated, nor structurally determined, and even though silylated phosphite was used, no 1,2-addition products could be observed.

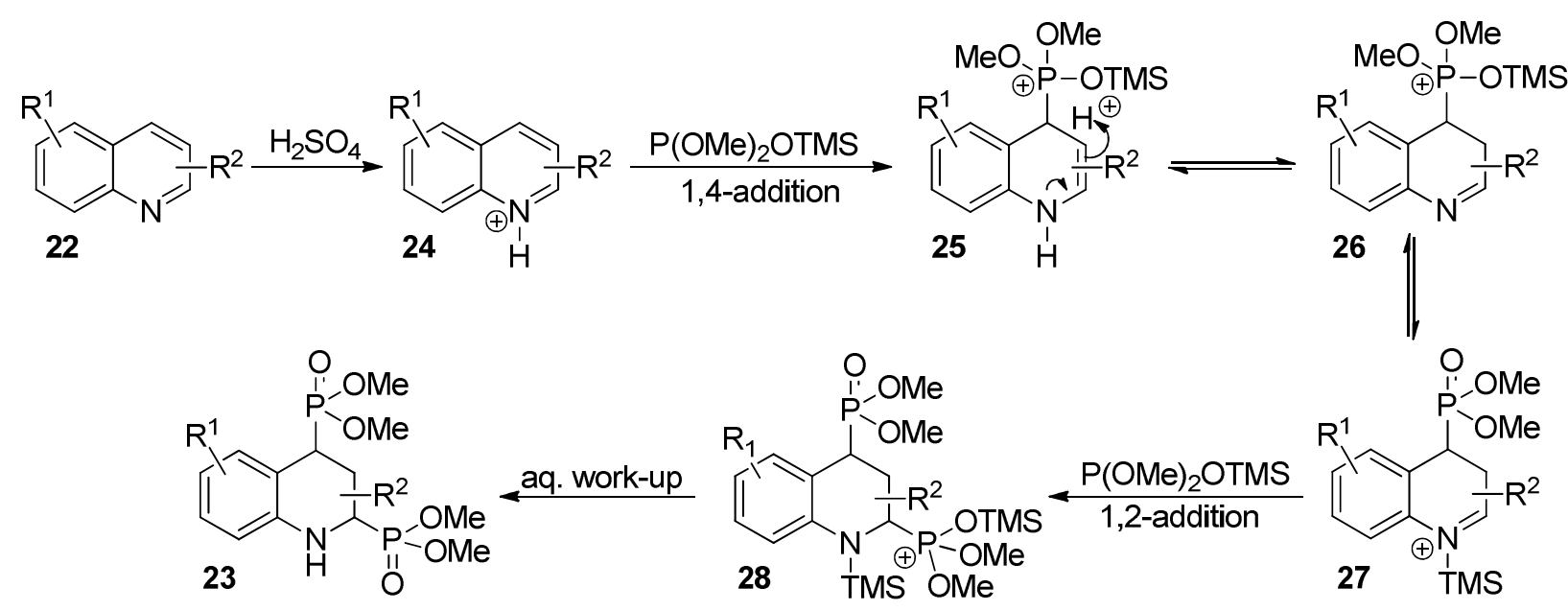

Scheme 15. Proposed reaction mechanism for the diphosphonylation of quinolines.

In order to shorten the reaction time, the tandem 1,4-1,2-addition was also evaluated under more stringent heating conditions, using microwave (MW) irradiation. Table 7 gives an overview of the synthesized derivatives. The usual acid-base extraction was used to purify the end products. In some cases, further chromatographic purification was required leading to lower yields than aspired because of the high affinity of 2,4-diphosphono-1,2,3,4-tetrahydroquinolines to silica. In the case of 3-methylquinoline, four pairs of diastereoisomers were expected to appear in the ${ }^{31} \mathrm{P}-\mathrm{NMR}$ 
spectrum because three stereocenters are formed during the 1,4-1,2-addition. However, only two pairs were detected after isolation of the end product.

Table 7. Substrate scope of the tandem addition using dimethyl trimethylsilyl phosphites (DMPTMS) to quinolines

\begin{tabular}{|c|c|c|c|c|c|c|}
\hline Entry & Product & & Equiv DMPTMS & Heating $^{\mathrm{a}}$ & Yield $(\%)^{\mathrm{b}}$ & d.r. \\
\hline $\begin{array}{l}1 \mathrm{a} \\
1 \mathrm{~b}\end{array}$ & & 23a & $\begin{array}{l}2.05 \\
2.05\end{array}$ & $\begin{array}{c}3 \text { days, } \Delta \\
2.5 \mathrm{~h}, \mathrm{MW}\end{array}$ & $\begin{array}{c}2(-) \\
36(-)\end{array}$ & $4: 96$ \\
\hline $\begin{array}{l}2 a^{c} \\
2 b^{c}\end{array}$ & & 23a & $\begin{array}{l}2.05 \\
2.05\end{array}$ & $\begin{array}{l}2 \text { days, } \Delta \\
3 \text { h, MW }\end{array}$ & $\begin{array}{l}15(48) \\
25(69)\end{array}$ & nd \\
\hline $\begin{array}{l}3 a \\
3 b\end{array}$ & & $23 b$ & $\begin{array}{l}3 \\
3\end{array}$ & $\begin{array}{l}6 \text { days, } \Delta \\
3 \text { h, MW }\end{array}$ & $\begin{array}{l}55(70) \\
60(76)\end{array}$ & $34: 66$ \\
\hline $\begin{array}{l}4 a \\
4 b\end{array}$ & & 23c & $\begin{array}{l}3 \\
3\end{array}$ & $\begin{array}{c}6 \text { days, } \Delta \\
3.5 \mathrm{~h}, \mathrm{MW}\end{array}$ & $\begin{array}{l}26(41) \\
53(69)\end{array}$ & $20: 80$ \\
\hline $\begin{array}{l}5 a \\
5 b\end{array}$ & & 23d & $\begin{array}{l}3 \\
3\end{array}$ & $\begin{array}{c}11 \text { days, } \Delta \\
4 \mathrm{~h}, \mathrm{MW}\end{array}$ & $\begin{array}{c}11(20) \\
2(9)\end{array}$ & $36: 64$ \\
\hline $\begin{array}{l}6 a \\
6 b\end{array}$ & & $23 e$ & $\begin{array}{l}3 \\
3\end{array}$ & $\begin{array}{c}4 \text { days, } \Delta \\
3.5 \text { h, MW }\end{array}$ & $\begin{array}{l}72(86) \\
64(75)\end{array}$ & $3: 97$ \\
\hline $\begin{array}{l}7 \mathrm{a} \\
7 \mathrm{~b}\end{array}$ & & $23 f$ & $\begin{array}{l}3 \\
3\end{array}$ & $\begin{array}{c}12 \text { days, } \Delta \\
4 \mathrm{~h}, \mathrm{MW}\end{array}$ & $\begin{array}{l}15(20) \\
19(27)\end{array}$ & $34: 66$ \\
\hline
\end{tabular}


Table 7. Continued

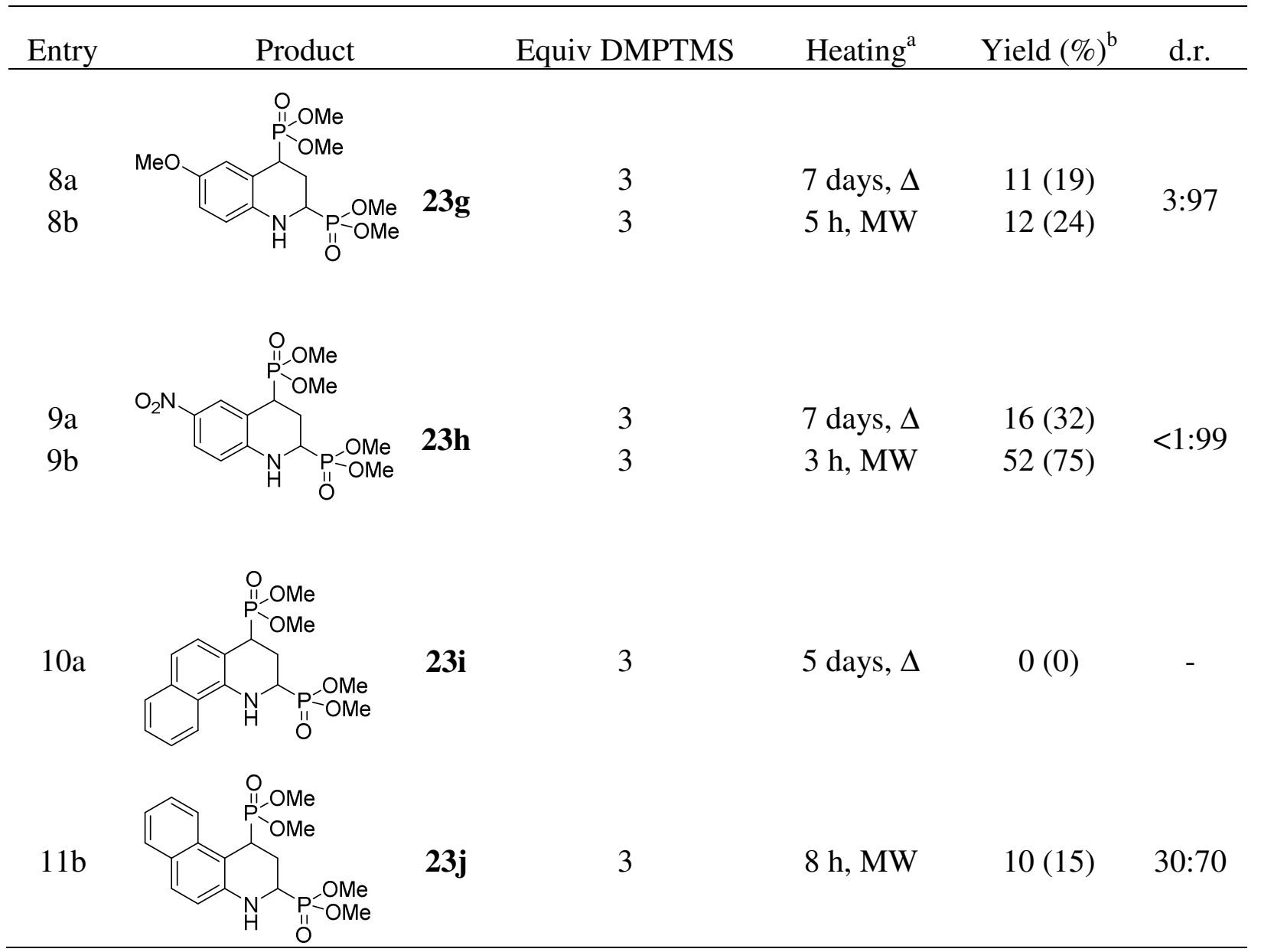

${ }^{\mathrm{a}} \Delta=$ reflux; $\mathrm{MW}=$ microwave heating $\left(45^{\circ} \mathrm{C}, 200 \mathrm{~W}\right){ }^{\mathrm{b}}$ Yield after acid-base extraction and subsequent column chromatography, conversion as determined by ${ }^{31} \mathrm{P}-\mathrm{NMR}$ is indicated in parentheses; ${ }^{\mathrm{c}}$ Reaction with $\mathrm{P}(\mathrm{OEt})_{2} \mathrm{OTMS}$ in $\mathrm{ClCH}_{2} \mathrm{CH}_{2} \mathrm{Cl}$.

From Table 7 it is clear that microwave heating (entries b), when compared to reflux conditions (entries a), generally leads to higher conversions and yields, in shorter reaction times. The use of $\mathrm{P}(\mathrm{OEt})_{2} \mathrm{OTMS}$ in combination with $\mathrm{ClCH}_{2} \mathrm{CH}_{2} \mathrm{Cl}$ as a higher boiling solvent did not improve the conversion to the 1,4-1,2-addition product (entry 2). Probably, the higher reaction temperature results in an increased degradation of the silylated phosphite to diethyl phosphite, which is a less reactive phosphonylation agent. Steric hindrance at the 4-position (entry 5) has a great influence on the conversion to the double addition product. This was also observed for the addition of $\mathrm{P}(\mathrm{OMe})_{2} \mathrm{OTMS}$ to $\alpha, \beta$-unsaturated hydrazones (Table 5). This is in line with the proposed reaction mechanism, which starts with a 1,4-addition. 2-Methylquinoline (entry 3) also showed a lower conversion, but to a lesser extent than 4-methylquinoline. 6-Methoxyquinoline (entry 8) gave lower yields than expected. This is probably caused by the presence of an extended conjugated system due to the mesomeric donating properties of the methoxy group. This results in a decreased 
electrophilicity of the $\mathrm{C}=\mathrm{N}$ bond, reducing the rate of 1,4-addition. Benzo[f]quinoline (entry 11) reacted much slower than unsubstituted quinoline.

\subsection{Phenanthrolines}

To further broaden the scope of the double phosphonylation of aromatic systems, different phenanthrolines were evaluated (Table 8). ${ }^{51}$ The reaction was performed under reflux conditions as well as under microwave irradiation.

Phenanthrolines are characterized by an extended aromatic system. The double addition of $\mathrm{P}(\mathrm{OMe})_{2} \mathrm{OTMS}$ to the different phenanthrolines is very slow under reflux conditions (entries a). Better conversions and yields were established under microwave heating. The position of the nitrogen atoms has a significant influence on the reaction (compare entry 1 to entries 2 and 3 ). In an attempt to increase the conversion of 1,7- and 4,7-phenanthroline, the phosphite and $\mathrm{H}_{2} \mathrm{SO}_{4}$ were added stepwise to reduce the hydrolysis of the silylated phosphite (entries 1e,f; 2c,d and 3d,e). However, the addition of dimethyl trimethylsilyl phosphite in portions did not lead to higher conversions.

Table 8. Substrate scope of the tandem addition using trimethylsilyl dimethyl phosphite (DMPTMS) to phenanthrolines

\begin{tabular}{|c|c|c|c|c|c|c|c|}
\hline Entry & Product & & $\begin{array}{c}\text { Equiv } \\
\text { DMPTMS }\end{array}$ & $\begin{array}{l}\text { Equiv } \\
\mathrm{H}_{2} \mathrm{SO}_{4}\end{array}$ & Heating $^{\mathrm{a}}$ & Yield $(\%)^{\mathrm{b}}$ & d.r. \\
\hline $1 \mathrm{a}$ & & & 2.05 & 0.5 & 5 days, $\Delta$ & $-(1)$ & - \\
\hline $1 b$ & & & 6 & 1 & $2 \mathrm{~h}, \mathrm{MW}$ & $88(95)$ & $7: 93$ \\
\hline $1 \mathrm{c}$ & & 20 & 3 & 0.5 & $3 \mathrm{~h}, \mathrm{MW}$ & $75(86)$ & $8: 92$ \\
\hline $1 d$ & & 29 & 3.5 & 0.5 & $5 \mathrm{~h}, \mathrm{MW}$ & $96(100)$ & $6: 94$ \\
\hline $1 \mathrm{e}$ & & & $3 \times 1$ & 0.5 & $5 \mathrm{~h}, \mathrm{MW}$ & $48(62)$ & $5: 95$ \\
\hline 1f & & & $3 \times 2$ & $3 \times 0.4$ & $5 \mathrm{~h}, \mathrm{MW}$ & $-(26)$ & nd \\
\hline $2 \mathrm{a}$ & & & 2.05 & 0.5 & 3 days, $\Delta$ & $-(0)$ & - \\
\hline $2 b$ & & 20 & 3 & 0.5 & $5 \mathrm{~h}, \mathrm{MW}$ & $25(67)$ & $1: 99$ \\
\hline $2 c$ & & 30 & $3 \times 1$ & 1 & $5 \mathrm{~h}, \mathrm{MW}$ & $12(35)$ & $2: 98$ \\
\hline $2 d$ & & & $3 \times 2$ & $3 \times 0.4$ & $5 \mathrm{~h}, \mathrm{MW}$ & - (20) & nd \\
\hline $3 a$ & & & 2.05 & 0.5 & 6 days, $\Delta$ & - (14) & nd \\
\hline $3 b$ & & & 4 & 1 & 1 day, $\Delta$ & - (1) & $9: 91$ \\
\hline $3 c$ & & 31 & 6 & 1 & $3 \mathrm{~h}, \mathrm{MW}$ & $12(36)$ & $10: 9$ \\
\hline $3 d$ & & & $3 \times 2$ & 1 & $5 \mathrm{~h}, \mathrm{MW}$ & $8(22)$ & 0 \\
\hline $3 e$ & & & $3 \times 2$ & $3 \times 0.4$ & $5 \mathrm{~h}, \mathrm{MW}$ & $-(15)$ & nd \\
\hline
\end{tabular}

${ }^{\mathrm{a}} \Delta=$ reflux; $\mathrm{MW}=$ microwave heating $\left(45^{\circ} \mathrm{C}, 200 \mathrm{~W}\right) ;{ }^{\mathrm{b}}$ Yield after acid-base extraction and subsequent column chromatography, conversion as determined by ${ }^{31} \mathrm{P}-\mathrm{NMR}$ is indicated in parentheses. 
A density functional theory (DFT) based computational study at the M06-2X/6-31+G(d,p) level of theory was performed to rationalize the observed experimental findings. The substrates were studied by calculating the proton affinities and nucleus-independent chemical shift (NCIS) values. The NICS values are used to quantify the aromaticity of the phenanthrolines and compared to those of quinolines and naphthyridines. It was found that the bicyclic species are more aromatic than the tricyclic ones in the order quinoline $>$ naphthyridine $>$ phenanthrolines. Protonation of a nitrogen atom increases the aromaticity of the entire system and leads to stable pyridinium ions, which is in line with the large proton affinities. Protonated quinoline is more stable than protonated naphthyridine which results in a higher activation barrier for quinoline. Overall however, experimentally, quinoline reacts faster than the other substrates. This can be rationalized taking into account the complete process of both protonation and phosphite addition (Figure 3a). Furthermore, based on the product stabilities addition to quinoline is favoured.

(a)

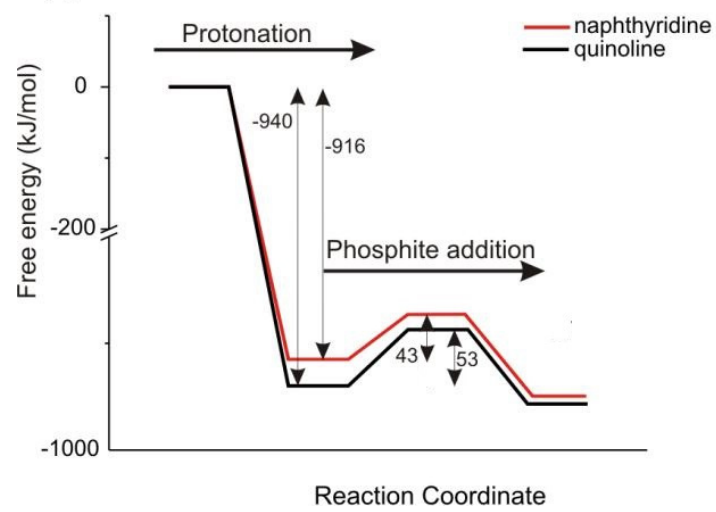

(b)

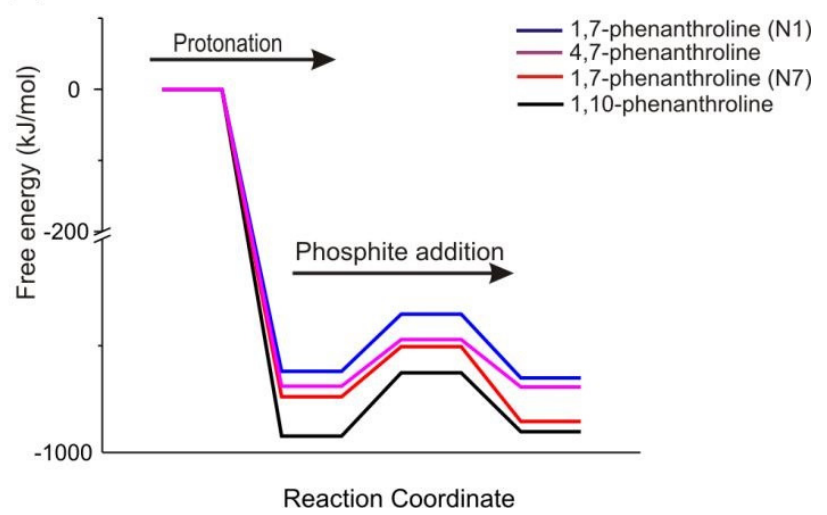

Figure 3. Phosphite addition to (a) quinoline and naphthyridine; and (b) phenanthrolines.

When the reactivity of the phenanthrolines is compared, the free-energy scheme is in line with the experimental findings which yield an overall preference for the phosphite addition at 1,10phenanthroline (Figure 3b). There is thus a substantial influence of the position of the nitrogen atoms.

\subsection{Naphthyridines}

The aforementioned DFT study revealed that the diphosphonylation of 1,5-naphthyridine would be feasible (Scheme 16). ${ }^{51}$

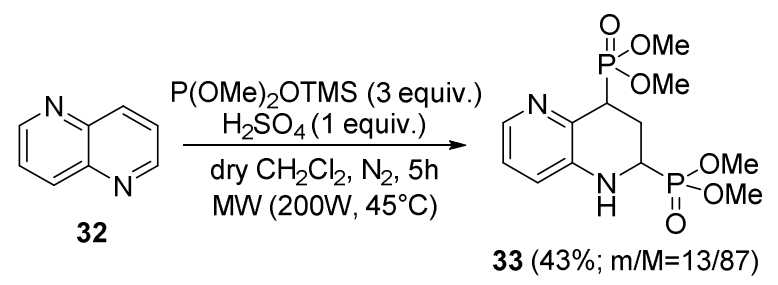

Scheme 16. Tandem 1,4-1,2-addition of silylated phosphite to 1,5-naphthyridine. 
To this end, 1,5-naphthyridine was dissolved in dry dichloromethane and $\mathrm{P}(\mathrm{OMe})_{2} \mathrm{OTMS}$ (3 equiv) and $\mathrm{H}_{2} \mathrm{SO}_{4}$ (1 equiv) were added. The mixture was stirred for 5 hours under microwave irradiation $\left(200 \mathrm{~W}, 45{ }^{\circ} \mathrm{C}\right) .{ }^{31} \mathrm{P}-\mathrm{NMR}$ analysis revealed $87 \%$ conversion of the starting material. After work-up, the end product was isolated in $43 \%$ yield. Compared to the addition of silylated phosphite to quinolines, 1,5-naphthyridine reacted much slower under the same conditions. Double 1,4-additions were not observed.

In contrast to 1,5-naphthyridine, no diphosphonylated product was observed when using 1,6-naphthyridine (Table 9). After 5 hours under microwave irradiation, only a limited conversion to two monophosphonylated products was observed (entry 2). These products could not be isolated and are most probably the 1,2- and the 1,4-addition product of $\mathrm{P}(\mathrm{OMe})_{2} \mathrm{OTMS}$ to 1,6-naphthyridine.

Table 9. Reaction of 1,6-naphthyridine with $\mathrm{P}(\mathrm{OMe})_{2} \mathrm{OTMS}$

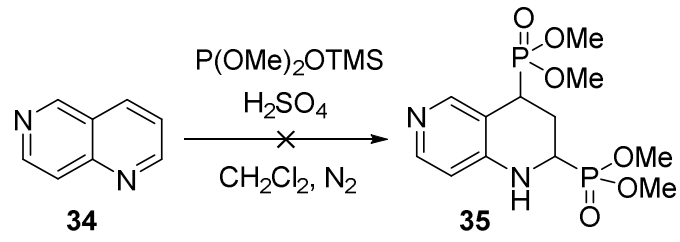

\begin{tabular}{ccccc}
\hline Entry & Equiv $\mathrm{P}(\mathrm{OMe})_{2} \mathrm{OTMS}$ & ${\text { Equiv } \mathrm{H}_{2} \mathrm{SO}_{4}}$ & Heating $^{\mathrm{a}}$ & Conversion $(\%)$ \\
\hline 1 & 3 & 0.5 & 3 days, $\Delta$ & - \\
2 & $3 \times 1$ & $3 \times 0.4$ & $5 \mathrm{~h}, \mathrm{MW}$ & 10 \\
3 & 3 & 1 & $5 \mathrm{~h}, \mathrm{MW}$ & - \\
\hline
\end{tabular}

${ }^{\mathrm{a}} \Delta=$ reflux; $\mathrm{MW}=$ microwave heating $\left(45^{\circ} \mathrm{C}, 200 \mathrm{~W}\right)$.

\subsection{Other aromatic heterocycles}

Other aromatic heterocycles besides quinolines, phenanthrolines and naphthyridines were also evaluated for the 1,4-1,2-addition of silylated phosphite, be it with limited success.

First, acridine was tested as substrate for the diphosphonylation reaction. The reaction was evaluated under reflux conditions and under microwave irradiation (Table 10). However, no diphosphonylation was observed for the different reaction conditions. In all cases, the monophosphonylated product, dimethyl (9,10-dihydroacridin-9-yl)phosphonate 37, was isolated.

Full conversion of acridine is obtained after $0.5 \mathrm{~h}$ under microwave irradiation (entries b). However, despite the excellent conversions, the isolated yield is low using the usual acid-base extraction. During the extraction of the $3 \mathrm{M} \mathrm{HCl}$ aqueous phase with $\mathrm{Et}_{2} \mathrm{O}$ to remove excess phosphite, significant amounts of product are lost in the organic phase. For this reason, the reaction mixture was quenched with $\mathrm{H}_{2} \mathrm{O}$ and extracted with $\mathrm{CH}_{2} \mathrm{Cl}_{2}$ after completion of the reaction. With this methodology, excellent isolated yields were obtained (entries 2-3). 
The reaction mechanism for the monophosphonylation of acridine is given in Scheme 17. After initial protonation and 1,4-addition of $\mathrm{P}(\mathrm{OMe})_{2} \mathrm{OTMS}$, the formed enamine 37 is included in the allcarbon aromatic system. The tautomerisation of this enamine to the corresponding imine $\mathbf{3 8}$ is unlikely, thereby preventing 1,2-addition.

Table 10. Reaction of acridine with $\mathrm{P}(\mathrm{OMe})_{2} \mathrm{OTMS}$

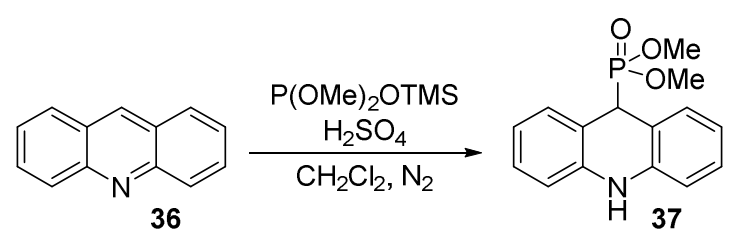

\begin{tabular}{ccccc}
\hline Entry & Equiv DMPTMS & Equiv $\mathrm{H}_{2} \mathrm{SO}_{4}$ & Heating $^{\mathrm{a}}$ & ${\text { Yield }(\%)^{\mathrm{b}}}^{\mathrm{b}}$ \\
\hline $\mathrm{a}$ & 2 & 0.5 & $3 \mathrm{~h}, \Delta$ & $16(92)$ \\
$1 \mathrm{~b}$ & 2 & 0.5 & $0.5 \mathrm{~h}, \mathrm{MW}$ & $45(100)$ \\
$\mathrm{2b}$ & 3 & 1 & $1 \mathrm{~h}, \mathrm{MW}$ & $76(100)^{\mathrm{c}}$ \\
$3 \mathrm{~b}$ & 2 & 0.5 & $0.5 \mathrm{~h}, \mathrm{MW}$ & $90(100)^{\mathrm{c}}$ \\
\hline
\end{tabular}

${ }^{\mathrm{a}} \Delta=$ reflux; $\mathrm{MW}=$ microwave heating $\left(45^{\circ} \mathrm{C}, 200 \mathrm{~W}\right) ;{ }^{\mathrm{b}}$ Yield after acid-base extraction and subsequent column chromatography, conversion as determined by ${ }^{31} \mathrm{P}-\mathrm{NMR}$ is indicated in parentheses; ${ }^{c}$ extraction with $\mathrm{H}_{2} \mathrm{O}$ and $\mathrm{CH}_{2} \mathrm{Cl}_{2}$.

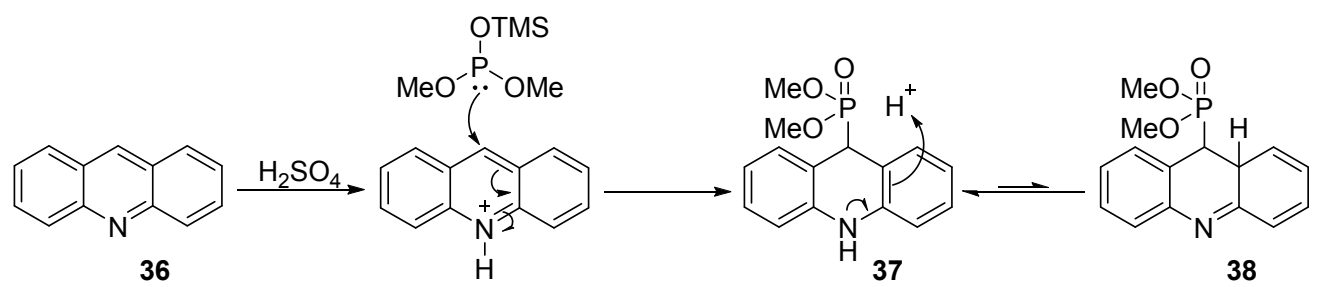

Scheme 17. Reaction mechanism for the monophosphonylation of acridine.

In a subsequent series of experiments, other aromatic heterocycles were evaluated (Table 11). Using pyridine (entry 1), no phosphite addition was observed. However, the reaction was only evaluated under reflux conditions.

Experiments with pyrimidine (entries 2-15) revealed no (entries 9-10, 12) or very limited conversions (entries 2-6, 8, 11). Using higher boiling solvents (entries 11-12) or more sulphuric acid (entries 9-10) did not improve the conversion. However, when the reaction was performed solvent free, a conversion of $57 \%$ was obtained (entry 7). Three new experiments were performed with a minimal amount of solvent to guarantee efficient mixing (entries 13-15). The best result was obtained with a minimal amount of $\mathrm{CH}_{2} \mathrm{Cl}_{2}$ under reflux conditions (entry 14). However, the formed 
product could not be isolated because of its limited stability. Probably, dimethyl (1,2dihydropyrimidine-2-yl)phosphonate is formed because the most reactive carbon atom is located between the two nitrogen atoms.

Table 11. Reaction of different aromatic heterocycles with $\mathrm{P}(\mathrm{OMe})_{2} \mathrm{OTMS}$

\begin{tabular}{|c|c|c|c|c|c|c|}
\hline Entry & Substrate & & $\begin{array}{c}\text { Equiv } \\
\text { DMPTMS }\end{array}$ & $\begin{array}{l}\text { Equiv } \\
\mathrm{H}_{2} \mathrm{SO}_{4}\end{array}$ & Heating $^{\mathrm{a}}$ & Yield $(\%)^{\mathrm{b}}$ \\
\hline 1 & & 39 & 2.05 & 0.5 & 2 days, $\Delta$ & $-(1)$ \\
\hline 2 & & & 3 & 0.5 & 6 days, $20^{\circ} \mathrm{C}$ & - (10) \\
\hline 3 & & & 3 & 1 & 4 days, $20^{\circ} \mathrm{C}$ & $-(4)$ \\
\hline 4 & & & 3 & 0.5 & 5 h, MW & $-(4)$ \\
\hline 5 & & & 3 & 1 & $5 \mathrm{~h}, \mathrm{MW}$ & $-(6)$ \\
\hline 6 & & & 3 & 1 & 4 days, $\Delta$ & $-(16)$ \\
\hline $7^{\mathrm{c}}$ & & & 3 & $2 \times 0.5$ & 4 days, $\Delta$ & $-(57)$ \\
\hline 8 & & 40 & 3 & $5 \times 0.25$ & 9 days, $\Delta$ & $-(27)$ \\
\hline 9 & & 40 & 3 & $2 \times 0.75$ & 3 days, $\Delta$ & $-(0)$ \\
\hline 10 & & & 3 & $2 \times 1$ & 5 days, $\Delta$ & $-(0)$ \\
\hline $11^{\mathrm{d}}$ & & & 3 & 1 & 6 days, $\Delta$ & $-(2)$ \\
\hline $12^{\mathrm{e}}$ & & & 3 & $4 \times 0.25$ & 8 days, $\Delta$ & $-(0)$ \\
\hline $13^{\mathrm{c}}$ & & & 3 & 1 & $5 \mathrm{~h}, \mathrm{MW}$ & - (64) \\
\hline 14 & & & 3 & 1 & 5 days, $\Delta$ & $7(84)$ \\
\hline $15^{\mathrm{d}}$ & & & 3 & 1 & 3 days, $\Delta$ & $-(27)$ \\
\hline 16 & & & $3 \times 1$ & 1 & 6 days, $\Delta$ & $13(45)$ \\
\hline 17 & & & 3 & 1.5 & 2 days, $\Delta$ & - (0) \\
\hline 18 & & 41 & 3 & 1 & $5 \mathrm{~h}, \mathrm{MW}$ & $7(36)$ \\
\hline $19^{\mathrm{d}}$ & & & 3 & 1 & 5 days, $\Delta$ & $11(41)$ \\
\hline $20^{\mathrm{e}}$ & & & 3 & 1 & 5 days, $\Delta$ & $5(27)$ \\
\hline 21 & & & 3 & 1 & 4 days, $20^{\circ} \mathrm{C}$ & $3(12)$ \\
\hline 22 & & & 3 & 1 & 6 days, $\Delta$ & $5(20)$ \\
\hline 23 & & & 3 & 1.5 & 5 days, $\Delta$ & $-(0)$ \\
\hline 24 & & 42 & 3 & 1 & $5 \mathrm{~h}, \mathrm{MW}$ & $4(14)$ \\
\hline $25^{\mathrm{d}}$ & & & 3 & 1 & 2 days, $\Delta$ & $-(6)$ \\
\hline $26^{\mathrm{e}}$ & & & 3 & 1 & 2 days, $\Delta$ & $-(4)$ \\
\hline
\end{tabular}

${ }^{\mathrm{a}} \Delta=$ reflux; $\mathrm{MW}=$ microwave heating $\left(45^{\circ} \mathrm{C}, 200 \mathrm{~W}\right) ;{ }^{\mathrm{b}}$ Yield after acid-base extraction and subsequent column chromatography, conversion as determined by ${ }^{31} \mathrm{P}-\mathrm{NMR}$ is indicated in parentheses; ${ }^{\mathrm{c}}$ no solvent; ${ }^{\mathrm{d}} \mathrm{ClCH}_{2} \mathrm{CH}_{2} \mathrm{Cl} ;{ }^{\mathrm{e}} \mathrm{CH}_{3} \mathrm{CN}$. 
The reactions with pyridazine (entries 16-20) were performed with a minimal amount of solvent in analogy with the results obtained with pyrimidine under these reaction conditions. The best results were obtained under reflux conditions and sequential addition of $\mathrm{P}(\mathrm{OMe})_{2} \mathrm{OTMS}$ (entry 16). No reaction was observed when the amount of $\mathrm{H}_{2} \mathrm{SO}_{4}$ was increased (entry 17). As with pyrimidine, performing the reaction in a higher boiling solvent did not improve the conversion (entries 19-20). However, instead of the 1,4-1,2-addition product, its methylated form (tetramethyl (2-methyl2,3,4,5-tetrahydropyridazine-3,5-diyl)bisphosphonate) was isolated. It is known that methylation of amines can occur in the presence of dialkyl phosphites. ${ }^{52-53}$ Dimethyl phosphite can be formed by hydrolysis of $\mathrm{P}(\mathrm{OMe})_{2} \mathrm{OTMS}$ in the presence of $\mathrm{H}_{2} \mathrm{SO}_{4}$.

The addition reactions to ftalazine were also performed with a minimal amount of solvent. The best results were obtained under reflux conditions (entry 22). Performing the reaction in a higher boiling solvent (entries 25-26) or with more $\mathrm{H}_{2} \mathrm{SO}_{4}$ (entry 23) had no beneficial effect on the conversion. The product formed could be isolated and was identified as the methylated monoaddition product of $\mathrm{P}(\mathrm{OMe})_{2} \mathrm{OTMS}$ to ftalazine: dimethyl (2-methyl-1,2-dihydroftalazine-1yl)phosphonate.

\subsection{Other activation methods}

The one-pot tandem 1,4-1,2-addition with sulphuric acid activation works well for the addition of $\mathrm{P}(\mathrm{OMe})_{2} \mathrm{OTMS}$ to aldimines, hydrazones and quinolines. However, the synthesis of other phosphonylated aromatic heterocycles with this method is less efficient. In this respect, super acids were evaluated for the activation of the substrates.

In a first experiment, trifluoromethanesulfonic acid was used for the diphosphonylation of quinoline (Scheme 18).

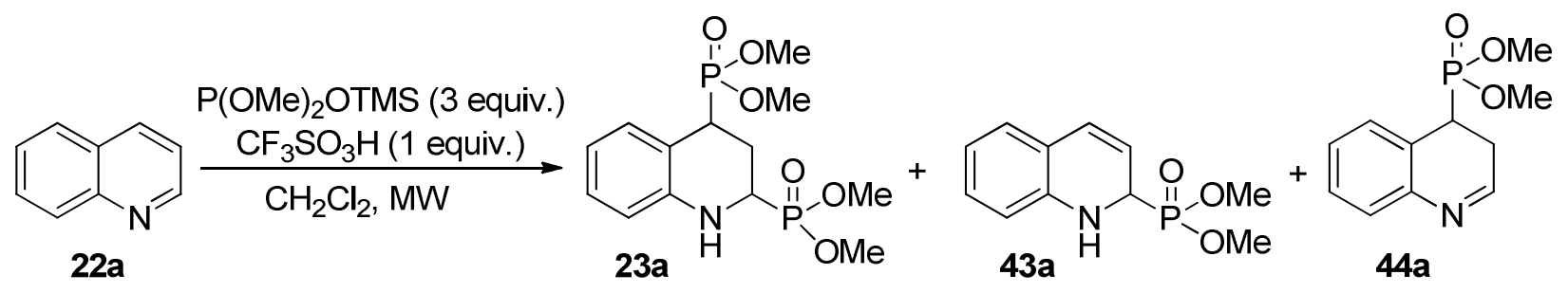

Scheme 18. Diphosphonylation of quinoline with $\mathrm{P}(\mathrm{OMe})_{2} \mathrm{OTMS}$ and $\mathrm{CF}_{3} \mathrm{SO}_{3} \mathrm{H}$.

After 3 hours, the reaction mixture was purified with the usual acid-base extraction. From the ${ }^{31} \mathrm{P}-\mathrm{NMR}$ spectrum, it was clear that the double 1,4-1,2-addition product was formed but as a minor side product. In the ${ }^{31} \mathrm{P}-\mathrm{NMR}$ spectrum, two other major peaks were observed. Probably, these peaks can be assigned to the two monophosphonylated products.

Subsequently, 'Olah's magic acid' $\left(\mathrm{FSO}_{3} \mathrm{H} . \mathrm{SbF}_{5}\right)$ was used for the evaluation of the addition of $\mathrm{P}(\mathrm{OMe})_{2} \mathrm{OTMS}$ to 3-methylquinoline (Scheme 19). 


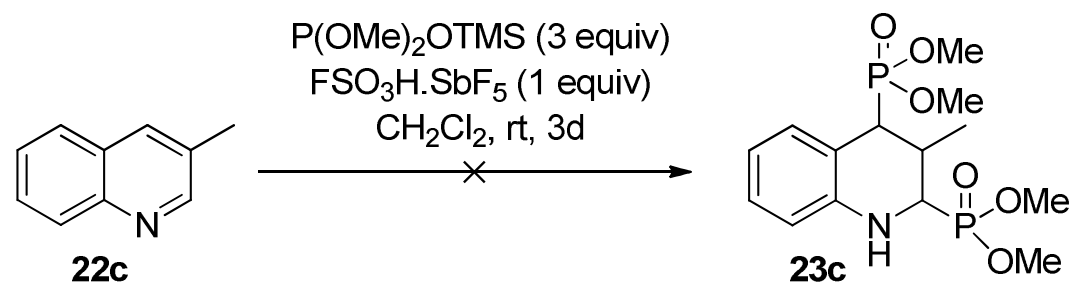

Scheme 19. Tandem 1,4-1,2-addition of $\mathrm{P}(\mathrm{OMe})_{2} \mathrm{OTMS}$ to 3-Me-quinoline.

The reaction with 'Olah's magic acid' reached a maximum conversion (39\%) after 3 days at room temperature. The resulting diphosphonylated product could be isolated with a yield of $4 \%$, but its ${ }^{31} \mathrm{P}$-NMR spectrum was inconsistent with the expected 1,4-1,2-addition product. Despite careful analysis of the ${ }^{1} \mathrm{H}-,{ }^{13} \mathrm{C}$-, HSQC-, COSY- and HMBC-spectra and mass spectra, the structure of the isolated product remains unclear.

The activation of the aromatic heterocycles with triflic anhydride is another strategy that was evaluated (Scheme 20). The activation of quinoline with triflic anhydride is based on the procedure of Haase et al. ${ }^{54}$ After activation, the 1,4-1,2-addition with silylated diethyl phosphite was evaluated. The reaction proceeds faster $(63 \%$ conversion after $21 \mathrm{~h})$ compared to the diphosphonylation with $\mathrm{P}(\mathrm{OMe})_{2} \mathrm{OTMS}$ and sulphuric acid under reflux conditions (Table 7, entry 1). However, the maximum conversion (63\%) and isolated yield (36\%) are lower.

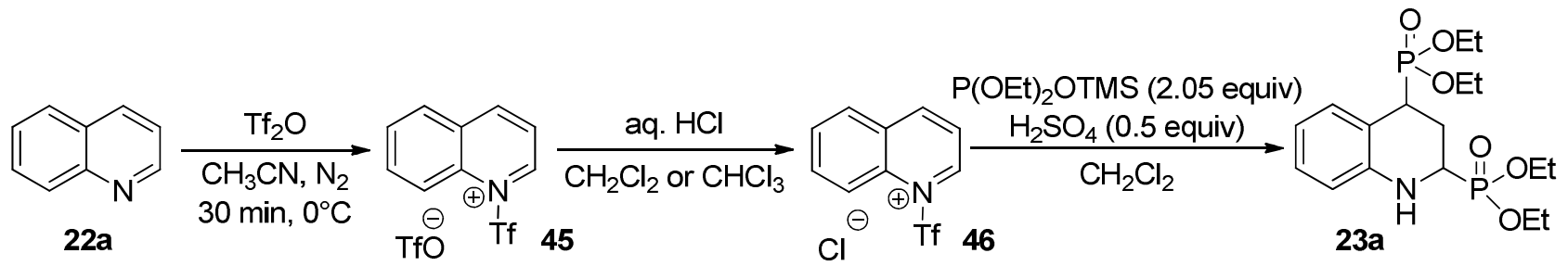

Scheme 20. Activation of quinoline with triflic anhydride.

\subsection{Double diphosphonylation}

The phenanthrolines were evaluated in a double diphosphonylation reaction because two $\alpha, \beta$-unsaturated systems are present (Scheme 21).

First, a one-pot procedure was evaluated using 6 equivalents $\mathrm{P}(\mathrm{OMe})_{2} \mathrm{OTMS}$ and 1 equivalent $\mathrm{H}_{2} \mathrm{SO}_{4}$ under microwave irradiation. However, only signals of the diphosphonylated products were detected in the ${ }^{31} \mathrm{P}-\mathrm{NMR}$ spectrum. Next, the isolated diphosphonylated products were again reacted with 3 equivalents $\mathrm{P}(\mathrm{OMe})_{2} \mathrm{OTMS}$ and 0.5 equivalent $\mathrm{H}_{2} \mathrm{SO}_{4}$. Again, no reaction to the tetraphosphonylated products was observed. The results are summarised in Table 12. 


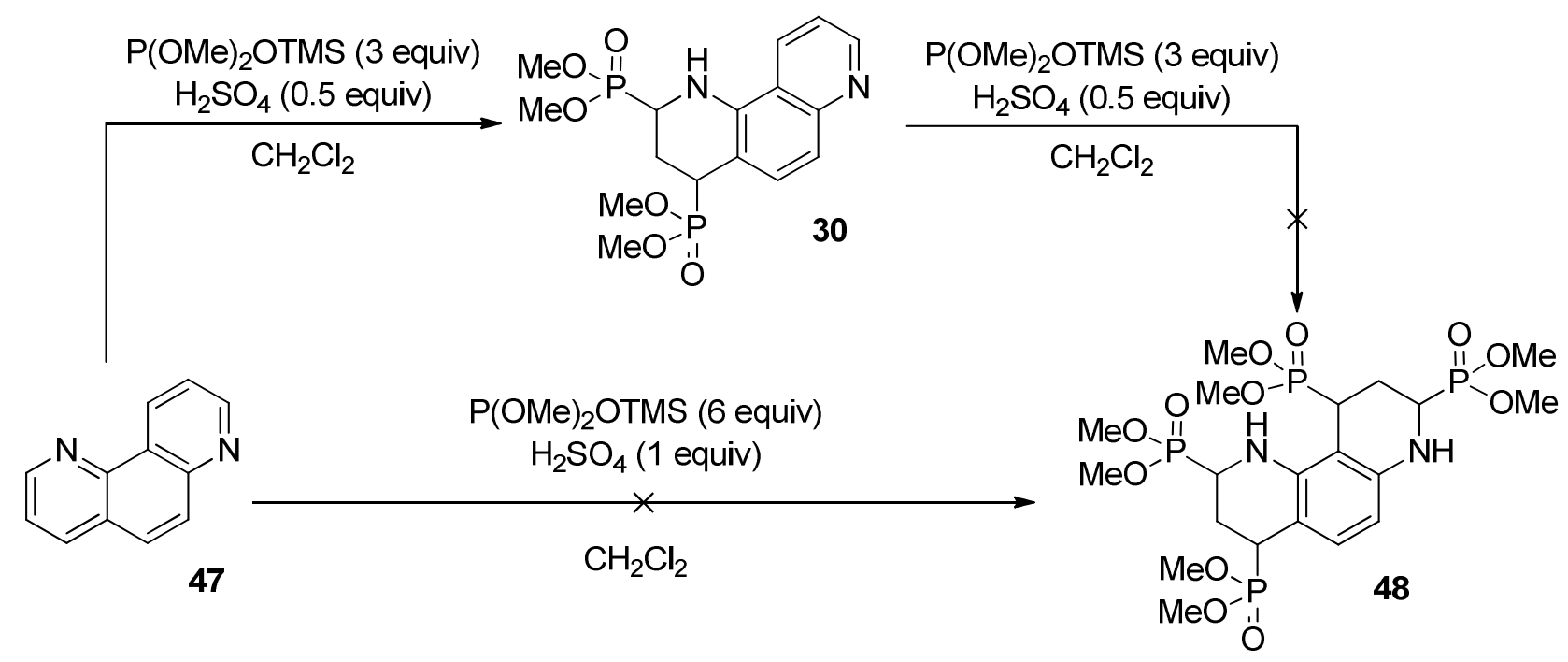

Scheme 21. Attempted double diphosphonylation of 1,7-phenanthroline.

Table 12. Attempted double diphosponylation of phenanthrolines

\begin{tabular}{|c|c|c|c|c|c|c|}
\hline Entry & Substrate & $\begin{array}{c}\text { Equiv } \\
\text { DMPTMS }\end{array}$ & $\begin{array}{c}\text { Equiv } \\
\text { acid }\end{array}$ & Acid & Heating $^{\mathrm{a}}$ & Conversion \\
\hline 1 & & 6 & 1 & $\mathrm{H}_{2} \mathrm{SO}_{4}$ & $2 \mathrm{~h}, \mathrm{MW}$ & - \\
\hline 2 & & 3 & 0.5 & $\mathrm{H}_{2} \mathrm{SO}_{4}$ & $3 \mathrm{~h}, \mathrm{MW}$ & - \\
\hline 3 & & 6 & 1 & $\mathrm{H}_{2} \mathrm{SO}_{4}$ & $5 \mathrm{~h}, \mathrm{MW}$ & - \\
\hline 4 & & 3 & 1 & $\mathrm{FSO}_{3} \mathrm{H} . \mathrm{SbF}_{5}$ & 2 days, $\Delta$ & - \\
\hline 5 & & 6 & 1 & $\mathrm{H}_{2} \mathrm{SO}_{4}$ & $3 \mathrm{~h}, \mathrm{MW}$ & - \\
\hline
\end{tabular}

${ }^{\mathrm{a}} \Delta=$ reflux; $\mathrm{MW}=$ microwave heating $\left(45^{\circ} \mathrm{C}, 200 \mathrm{~W}\right)$. 
After the initial 1,4-1,2-addition of $\mathrm{P}(\mathrm{OMe})_{2} \mathrm{OTMS}$ to the phenanthrolines, protonation of the aromatic nitrogen has to occur for a second 1,4-addition. However, the formed secondary amine will be protonated preferentially and the formation of a second cation is unlikely to happen. In this way, no protonation of the second aromatic nitrogen occurs, preventing a double diphosphonylation.

\subsection{Oxidation of the diphosphonylated products}

During the diphosphonylation reaction, the aromatic structure of the substrates is removed. Different oxidation reactions were evaluated to restore the aromaticity of the diphosphonylated products. Table 13 gives an overview of the evaluated methods. In all cases, restoring the aromaticity of the diphosphonylated products failed. When DDQ was used as oxidant, one of the phosphonate groups was cleaved off. In the two other oxidation methods, only starting material was recovered.

Table 13. Attempts to restore the aromaticity of the diphosphonylated products

\begin{tabular}{|c|c|c|c|c|c|c|}
\hline Entry & Product & & Oxidant & Solvent & Conditions & Conversion \\
\hline 1 & & & DDQ & Benzene & $4 \mathrm{~h}, 20^{\circ} \mathrm{C}$ & - \\
\hline 2 & & & DDQ & Dioxane $/ \mathrm{H}_{2} \mathrm{O}$ & $4 \mathrm{~h}, 20^{\circ} \mathrm{C}$ & - \\
\hline 3 & & 23a & Chloranil & $\mathrm{CH}_{2} \mathrm{Cl}_{2}$ & $1 \mathrm{~h}, 20^{\circ} \mathrm{C}$ & - \\
\hline 4 & & & Chloranil & $\mathrm{ClCH}_{2} \mathrm{CH}_{2} \mathrm{Cl}$ & $18 \mathrm{~h}, \Delta$ & - \\
\hline 5 & & & Chloranil & $\mathrm{ClCH}_{2} \mathrm{CH}_{2} \mathrm{Cl}$ & $96 \mathrm{~h}, \Delta$ & - \\
\hline 6 & $\begin{array}{l}\text { P-OMe } \\
\text { OI OMe }\end{array}$ & 30 & NCS & $\begin{array}{c}\text { a) } \mathrm{CCl}_{4} \\
\text { b) } \mathrm{KOH} / \mathrm{H}_{2} \mathrm{O}\end{array}$ & $\begin{array}{l}\text { a) } 24 \mathrm{~h}, 20^{\circ} \mathrm{C} \\
\text { b) } 18 \mathrm{~h}, \Delta\end{array}$ & - \\
\hline
\end{tabular}

\subsection{Synthesis of diphosphonic acids}

The method developed by McKenna was used to evaluate the hydrolysis of the phosphonate esters. $^{55}$ The hydrolysis was carried out by silylation of the ester moieties and subsequent alcoholysis with $\mathrm{MeOH}$ (Scheme 22). However, with this method a mixture of the phosphonic acid and a phosphonate monoester was obtained.

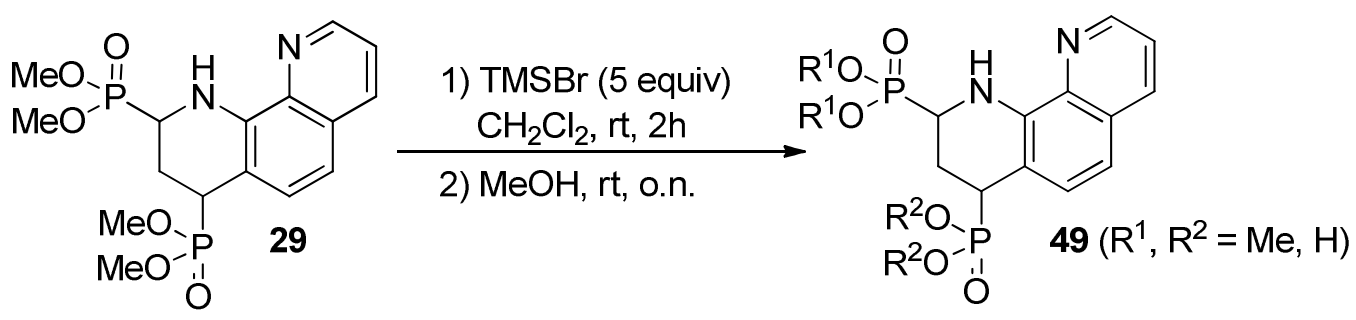

Scheme 22. Hydrolysis of the phosphonate ester moieties. 


\section{Conclusions}

In retrospect, the observation of a tandem 1,4-1,2-diphosphonylation of unsaturated imines has led us much further than anticipated. The detection of minor side products upon prolonging the reaction time of previously published reactions, and more importantly, the isolation of these side products has opened up a completely new line of research. It is now clear that, under the right conditions, not 1-aminophosphonates (APs) but 3-phosphonyl 1-aminoalkylphosphonate (PAPs) are the final reaction products of $\alpha, \beta$-unsaturated imines and $\sigma 3 \lambda 3$ phosphorous nucleophiles. Expansion of the methodology has led to the successful conversion of unsaturated imines and hydrazones, and the reminiscent aromatic substrates such as quinolines, phenanthrolines and naphthyridines. There is a clear difference in reactivity between trialkyl phosphites and trialkylsilyl dialkyl phosphites, but both reagents deliver the desired PAPs and appear to be complementary. Trialkyl phosphite is better suited for sterically less hindered imines, while its silylated counterpart performs better as the steric bulk increases.

\section{Acknowledgements}

Financial support for this research from the Fund for Scientific Research Flanders (FWO Vlaanderen) is gratefully acknowledged.

\section{References}

$¥$ These authors have contributed in equal amounts.

1. Moonen, K.; Laureyn, I.; Stevens, C. V. Chem. Rev. 2004, 6177-6215. http://dx.doi.org/10.1021/cr030451c

2. Kafarski, P.; Lejczak, B. Phosphorus Sulfur Silicon Relat. Elem. 1991, 193-215. http://dx.doi.org/10.1080/10426509108029443

3. Brauner-Osborne, H.; Egebjerg, J.; Nielsen, E.O.; Madsen, U.; Krogsgaard-Larsen, P. J. Med. Chem. 2000, (43), 2609-2645.

http://dx.doi.org/10.1021/jm000007r

4. Tanabe, Y.; Nomura, A.; Masu, M.; Shigemoto, R.; Mizuno, N.; Nakanishi, S. J. Neurosci. 1993, (13), 1372-1378.

5. Nakajima, Y.; Iwakabe, H.; Akazawa, C.; Nawa, H.; Shigemoto, R.; Mizuno, N.; Nakanishi, S. J. Biol. Chem. 1993, (268), 11868-11873.

6. Okamoto, N.; Hori, S.; Akazawa, C.; Hayashi, Y.; Shigemoto, R.; Mizuno, N.; Nakanishi, S. J. Biol. Chem. 1994, (269), 1231-1236.

7. Brauner-Osborne, H.; Krogsgaard-Larsen, P. Br. J. Pharmacol. 1998, (123), 269-274. http://dx.doi.org/10.1038/sj.bjp.0701616 
8. Johansen, P. A.; Chase, L.A.; Sinor, A. D.; Koerner, J. F.; Johnson, R. L.; Robinson, M. B. Mol. Pharmacol. 1995, (48), 140-149.

9. Olverman, H. J.; Jones, A. W.; Mewett, K. N.; Watkins, J. C. Neurosci. 1988, (26), 17-31. http://dx.doi.org/10.1016/0306-4522(88)90124-8

10. Darriet, M.; Basurko, M. J.; Cassaigne, A. Biochem. Soc. Trans. 1988, (16), 611-612.

11. Marche, M.; Basurko, M. J.; Cassaigne, A. Biochimie 1987, (69), 461-467. http://dx.doi.org/10.1016/0300-9084(87)90083-6

12. Bakuniak, E.; Bakuniak, I.; Borucka, B.; Ostrowski, J. J. Environ. Sci. Heal. B 1983, (18), 485496. http://dx.doi.org/10.1080/03601238309372383

13. Fields, E. K. J. Am. Chem. Soc. 1952, (74), 1528-31. http://dx.doi.org/10.1021/ja01126a054

14. Guthrie, J. P. Can. J. Chem. 1979, (57), 236-9. http://dx.doi.org/10.1139/v79-039

15. Cherkasov, R. A.; Galkin, V. I. Uspekhi Khimii 1998, (67), 940-968.

16. Keglevich, G.; Szekrenyi, A.; Kovacs, R.; Grun, A. Phosphorus, Sulfur Silicon Relat. Elem. 2009, (184), 1648-1652. http://dx.doi.org/10.1080/10426500902948003

17. Keglevich, G.; Balint, E. Molecules 2012, (17), 12821-12835. http://dx.doi.org/10.3390/molecules171112821

18. Wan, D.; Wu, M.; Ma, J. Youji Huaxue 2012, (32), 13-18.

19. Zefirov, N. S.; Matveeva, E. D. Arkivoc 2008, 1-17. http://dx.doi.org/10.3998/ark.5550190.0009.101

20. Afarinkia, K.; Rees, C. W.; Cadogan, J. I. G. Tetrahedron 1990, (46), 7175-7196. http://dx.doi.org/10.1016/S0040-4020(01)87899-6

21. Teulade, M.-P.; Savignac, P. Synthesis 1987, (1987), 1037-1039. http://dx.doi.org/10.1055/s-1987-28165

22. Afarinkia, K.; Cadogan, J. I. G.; Rees, C. W. Synlett. 1992, 123-123. http://dx.doi.org/10.1055/s-1992-21286

23. Vanderhoydonck, B.; Stevens, C. V. Synthesis 2004, 722-734. http://dx.doi.org/10.1055/s-2004-815969

24. Ghelfi, F.; Stevens, C. V.; Laureyn, I.; Van Meenen, E.; Rogge, T. M.; De Buyck, L.; Nikitin, K. V.; Grandi, R.; Libertini, E.; Pagnoni, U. M.; Schenetti, L. Tetrahedron 2003, (59), 11471157. http://dx.doi.org/10.1016/S0040-4020(03)00044-9

25. Stevens, C. V.; Vekemans, W.; Moonen, K.; Rammeloo, T. Tetrahedron Lett. 2003, (44), 16191622. http://dx.doi.org/10.1016/S0040-4039(03)00005-4

26. Mortier, P. P. J.; Van Waes, F. E. A.; Masschelein, K. G. R.; Heugebaert, T. S. A.; Stevens, C. V. Tetrahedron Lett. 2011, (52), 4273-4276. http://dx.doi.org/10.1016/j.tetlet.2011.05.149 
27. Moonen, K.; Van Meenen, E.; Verwee, A.; Stevens, C. V. Angew. Chem. Int. Ed. 2005, (44), 7407-7411. http://dx.doi.org/10.1002/anie.200501830

28. Van Meenen, E.; Moonen, K.; Verwée, A.; Stevens, C. V. J. Org. Chem. 2006, (71), 7903-7906. http://dx.doi.org/10.1021/jo061256b

29. Chandrasekhar, S.; Prakash, S. J.; Jagadeshwar, V.; Narsihmulu, C. Tetrahedron Lett. 2001, (42), 5561-5563. http://dx.doi.org/10.1016/S0040-4039(01)01053-X

30. Chandrasekhar, S.; Narsihmulu, C.; Sultana, S. S.; Saritha, B.; Prakash, S. J. Synthesis 2003, 505-506.

http://dx.doi.org/10.1055/s-2003-37508

31. Heydari, A.; Karimian, A.; Ipaktschi, J. Tetrahedron Lett. 1998, (39), 6729-6732. http://dx.doi.org/10.1016/S0040-4039(98)01411-7

32. Ranu, B. C.; Hajra, A.; Jana, U. Org. Lett. 1999, (1), 1141-1143. http://dx.doi.org/10.1021/o1990079g

33. Kaboudin, B.; Nazari, R. Tetrahedron Lett. 2001, (42), 8211-8213. http://dx.doi.org/10.1016/S0040-4039(01)01627-6

34. Kudrimoti, S.; Bommena, V. R. Tetrahedron Lett. 2005, (46), 1209-1210. http://dx.doi.org/10.1016/j.tetlet.2004.12.070

35. Shimizu, M.; Morita, A.; Kaga, T. Tetrahedron Lett. 1999, (40), 8401-8405. http://dx.doi.org/10.1016/S0040-4039(99)01794-3

36. Evans, D. A.; Hurst, K. M.; Takacs, J. M. J. Am. Chem. Soc. 1978, (100), 3467-77. http://dx.doi.org/10.1021/ja00479a031

37. Abramov, V. S. Dokl. Akad. Nauk SSSR 1954, (95), 991-2.

38. Gazizov, T. K.; Karelov, A. A.; Sudarev, Y. I.; Pudovik, A. N. Zh. Obshch. Khim. 1983, (53), 276-81.

39. Kirby, A. J.; Warren, S. G. The Organic Chemistry of Phosphorus (Reaction Mechanisms in Organic Chemistry, Monograph 5). Elsevier: Oxford, 1967; p 480.

40. Karimi-Jaberi, Z.; Zare, H.; Amiri, M.; Sadeghi, N. Chin. Chem. Lett. 2011, (22), 559-562. http://dx.doi.org/10.1016/j.cclet.2010.11.034

41. Karimi-Jaberi, Z.; Amiri, M.; Sadeghi, N. Synth. Commun. 2010, (40), 2948-2953. http://dx.doi.org/10.1080/00397910903340728

42. Akbari, J.; Heydari, A. Tetrahedron Lett. 2009, (50), 4236-4238. http://dx.doi.org/10.1016/j.tetlet.2009.05.020

43. Heydari, A.; Khaksar, S.; Tajbakhsh, M. Tetrahedron Lett. 2009, (50), 77-80. http://dx.doi.org/10.1016/j.tetlet.2008.10.106

44. Ramalingam, S.; Kumar, P. Catal. Lett. 2008, (125), 315-319. http://dx.doi.org/10.1007/s10562-008-9562-x

45. Tajbakhsh, M.; Heydari, A.; Alinezhad, H.; Ghanei, M.; Khaksar, S. Synthesis 2008, 352-354. http://dx.doi.org/10.1055/s-2008-1032034

46. Heydari, A.; Arefi, A. Catal. Commun. 2007, (8), 1023-1026. 


\section{http://dx.doi.org/10.1016/j.catcom.2006.10.019}

47. Stevens, C. V.; Van Meenen, E.; Masschelein, K. G. R.; Moonen, K.; De Blieck, A.; Drabowicz, J. Synlett 2007, (2007), 2549-2552. http://dx.doi.org/10.1055/s-2007-986654

48. Âbele, E.; Lukevics, E. Org. Prep. Proc. Int. 2000, (32), 235-264. http://dx.doi.org/10.1080/00304940009355921

49. Yang, S. H.; Chang, S. Org. Lett. 2001, (3), 4209-4211.

\section{http://dx.doi.org/10.1021/o10168768}

50. De Blieck, A.; Masschelein, K. G. R.; Dhaene, F.; Rozycka-Sokolowska, E.; Marciniak, B.; Drabowicz, J.; Stevens, C. V. Chem. Commun. 2010, (46), 258-260. http://dx.doi.org/10.1039/b906808b

51. De Blieck, A.; Catak, S.; Debrouwer, W.; Drabowicz, J.; Hemelsoet, K.; Verstraelen, T.; Waroquier, M.; Van Speybroeck, V.; Stevens, C. V. Eur. J. Org. Chem. 2013, 1058-1067. http://dx.doi.org/10.1002/ejoc.201201437

52. Maier, L. Phosphorus Sulfur Silicon Relat. Elem. 1991, (62), 29-34. http://dx.doi.org/10.1080/10426509108034455

53. Gancarz, R. Phosphorus Sulfur Silicon Relat. Elem. 1994, (92), 193-199. http://dx.doi.org/10.1080/10426509408021472

54. Haase, M.; Gunther, W.; Gorls, H.; Anders, E. Synthesis 1999, 2071-2081. http://dx.doi.org/10.1055/s-1999-3627

55. McKenna, C. E.; Higa, M. T.; Cheung, N. H.; McKenna, M. C. Tetrahedron Lett. 1977, 155158.

\section{http://dx.doi.org/10.1055/s-1999-3627}

\section{Authors' Biographies}

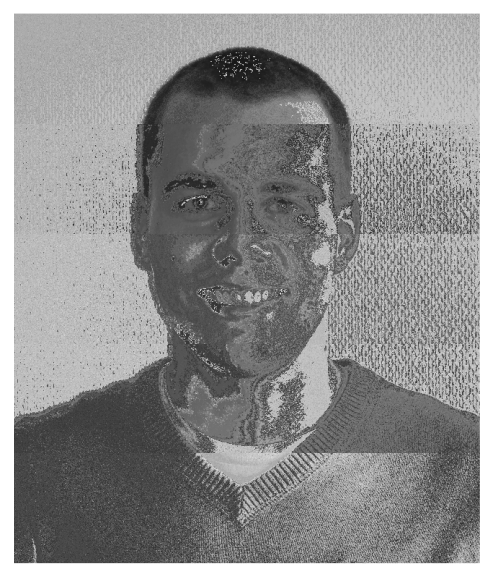

Ir. Frederik Van Waes (1987) graduated from Ghent University in 2010 as Master in Bioscience Engineering - Chemistry and biotechnology. In his master thesis, he studied the development of new tricyclic amino acid derivatives with potential antifeedant properties. He then joined the Department of Sustainable Organic Chemistry and Technology, research group SynBioc, as a 
doctoral researcher under the supervision of Prof. C. Stevens. His research focuses on the use of micro- and millireactor technology for batch reactions difficult to scale-up in organic chemistry.

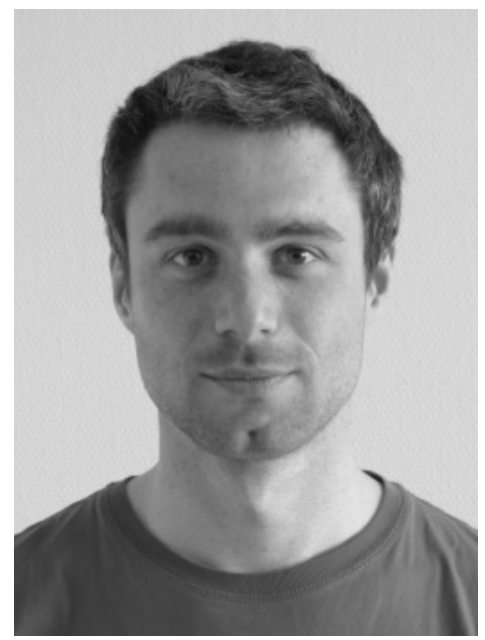

Ir. Wouter Debrouwer (1988) was born in Veurne, Belgium and was granted a Master's degree in Bioscience Engineering at Ghent University in 2011. His master thesis aimed at the synthesis of azacarbazoles utilizing gold catalysis. He subsequently started his $\mathrm{PhD}$ under the guidance of Prof. C. Stevens at the research group SynBioC, department of Substainable Organic Chemistry and Technology. His main research interests are phosphonate chemistry, azaheterocycles and alkyne activation.

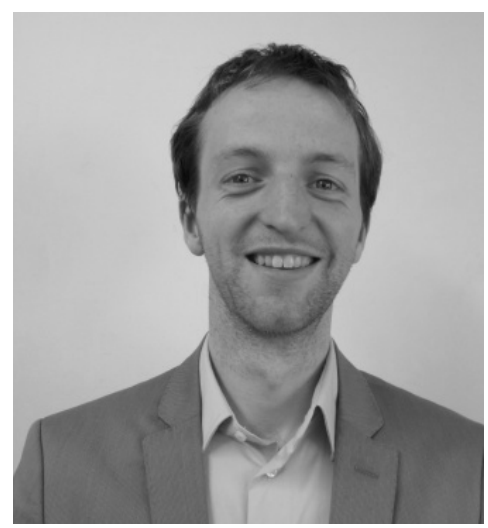

Dr. Ir. Thomas Heugebaert (1984) obtained his degree in Bioscience Engineering in 2007 from Ghent University, Belgium. There, he joined the Department of Sustainable Organic Chemistry and Technology, research group SynBioc, under the guidance of Prof. Christian Stevens. He obtained his $\mathrm{Ph}$. D. in 2012, studying gold catalysis and its application in the synthesis of biologically active organic molecules, including plant hormones, azaheterocyclic analgesics and five-membered heteroaromatic compounds. His current postdoctoral research, which is performed in part at the Institute of Chemistry, University of Graz, Austria, under the guidance of Prof. Oliver Kappe, focuses on the development of microreactor technology, improving its efficiency for gas/liquid interface photochemistry. 


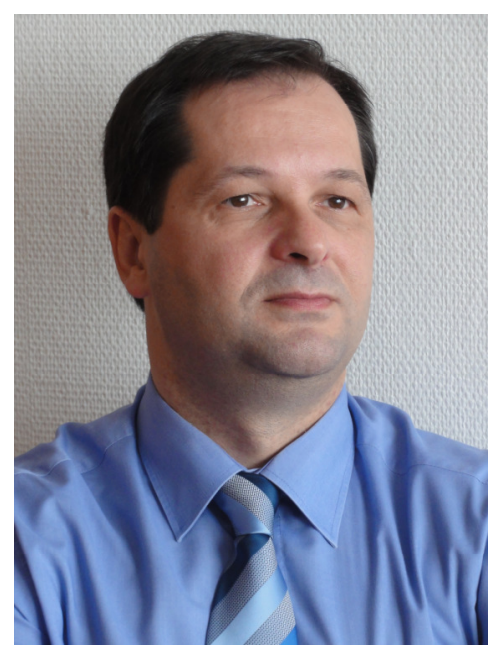

Prof. Dr. Ir. Christian V. Stevens (1965) is full professor at the Department of Sustainable Organic Chemistry and Technology at the Faculty of Bioscience Engineering (Ghent University, Belgium). He graduated in 1988 and obtained a PhD in 1992 at Ghent University. He then performed post doctoral work at the University of Florida guided by Prof. Alan Katritzky in 199293. In 2000, he became associate professor and full professor in 2008. C. Stevens published over 190 international peer reviewed papers and 14 patents. His research interest focuses on synthetic heterocyclic chemistry for agrochemical and medicinal applications, on chemical modification of renewable resources and on the use of flow chemistry to scale-up organic reactions that are difficult to scale-up in batch. 